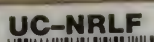

|||||-N \$B 34 b2 3

$\frac{c}{c v}$
$\frac{v}{c v}$
$v$ 


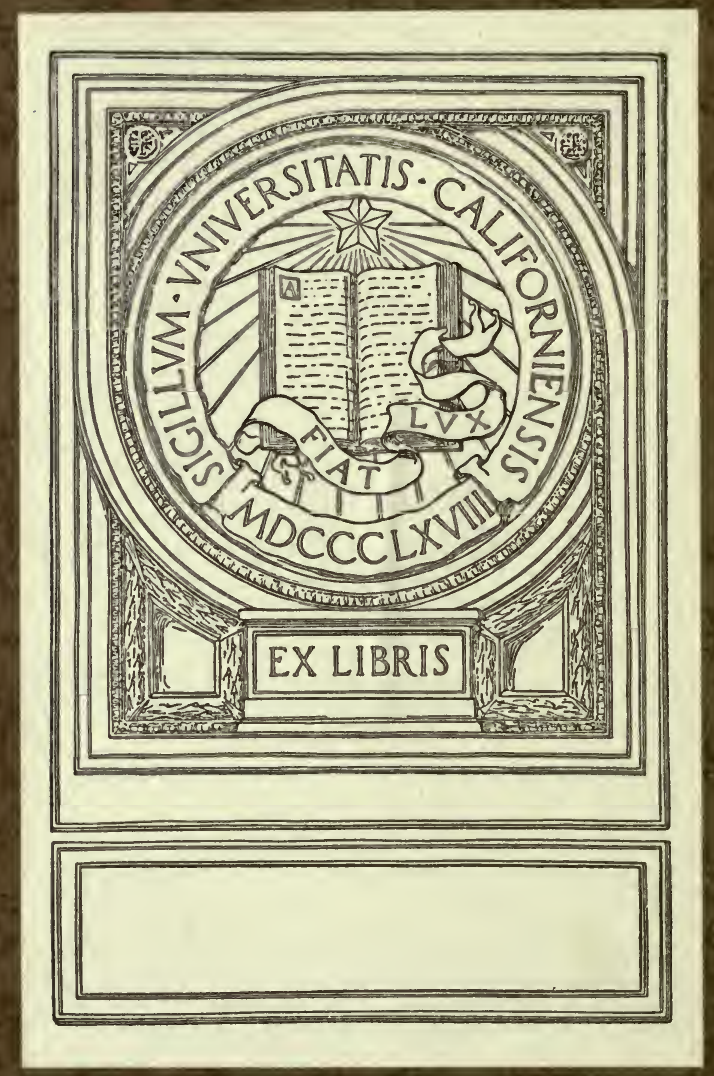



Digitized by the Internet Archive in 2007 with funding from Microsoft Corporation 


\section{THE INDUSTRIAL COLLEGES.}

THE NA'TURE OF THE EDUCATION 'TO BE GIVEN IN THEI; THEIR SEVERAL KINDS AND COURSES OF INSTRUCTION CONSIDERED.

$$
\text { BY LEWIS BOLLMAN. }
$$

TO WHICII IS ADDED

A COMMUNICATION ON THE GENERAL PLAN OF THE COLLEGE BUILDING, WITH THE NECESSARY AIDS TO INSTRUCTION IN EACH DEPARTMENT OF EDUCATION,

$$
\text { BY RICHARD OWEN, }
$$

PROFESSOR OF SCIENCE IN INDIANA STATE UNIVERSITY.

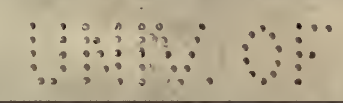

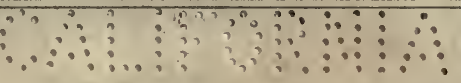

$\operatorname{rec} 1264 \%$ ? 


$$
5 \frac{53^{3}}{136}
$$

\%

$$
\begin{array}{r}
4 \\
\ddots \\
\vdots \\
\vdots
\end{array}
$$




\section{To the Industrial Classes:}

Wasuington, December 10, 186,

Occupying the position of statistician in the Department of Agriculture, it is my duty to examine the letters of its correspondents relative to the crops. Many of them, from time to time, have desired information on the best plat? to: establish the Industrial Colleges, for the endowment of which land donations have been made by Congress. It was not proper to overlook their requests, for the reason especially that, as yet, little has been written on such plan, either as to the general character of the instruction that should be given in these colleges, or on their special courses of instruction, or on the plans of their buildings, workshops, and experimental farms.

In complying with the wishes of these correspondents, and of others, it has been my aim to communicate some information on all of these important topics. The article is divided into three parts. The first contains my own views of the general nature of the education that ought to be given in these colleges, and the practical purposes such education should aim to accomplish; the second shows the particular courses of instruction given in European agricultural schools; and the third exhibits the plan of the buildings, the extent and arrangement of the museum, \&c., of an industrial college. What is stated in the second part is taken mostly from the recent and excellent report of $\mathrm{Mr}$. Flint, who has visited these schools, to the Massachusetts State Board of Agriculture. The third part has been kindly prepared, at my request, by Richard Owen, professor of science in Indiana State University, a brother of the late David Dale Owen, and one not less eminent in scientific attainments. It will be found to be the most important part of this article, especially to legislators, and others upon whom will devolve the duty of selecting plans for the buildings, providing means for their erection, and for the purchase of the museum, apparatus, and library.

I have prepared this article not ignorant of the diversity of opinion that exists on the subject of industrial education; but, whether opposing or concurring in any views therein expressed, all should remember that it is only by an examination of diverse opinions that those which are correct can be ascertained. It has been prepared, too, not without the hope that it will aid in the successful establishment of the industrial colleges, upon a basis as enlarged as is the magnitude of the interests of the industrial classes in them, and upon a plan that will secure their success, so that, by their success, they will vindicate the right of the industrial classes to equal instruction with that claimed for the professions.

LEWIS BOLLMAN. 

above that of the lawyer. A man may be but a mere lawyer, or a mere physician, or a mere farmer; they may know but the art alone of their respective pursuits, but the legal maxim, that he knows not the law who knoweth not the reason thereof, is as applicable to the industrial pursuits as to the professional.

In recent years the progress of the arts has been rapid, "and men," says the" author of Friends in Council, "are not agitated as they used to be by speculative questions, for the material world has opened out before us, and we cannot but look at it, and must play with it and work at it." 'This material world can be opened out before us only through the sciences. Hence it is that no individual can intelligently pursue any one of the arts as an occupation without an acquaintance with science. Nor can any one limit his knowledge of science to the single art he follows, for the same principles of science are common to many of the arts. Each art has not its peculiar and distinct principles. But if it had, no one should limit his knowledge to it. "Man," the same writer remarks, "should be desirous of expanding his own nature, and the nature of others in all directions; of cultivating many pursuits; of bringing himself and those around him in contact with the universe in many points; of being a man, and not a machine. The sense of the beautiful, and the desire for comprehending nature, are not things implanted in men merely to be absorbed in producing and distributing the objects of our most obvious animal wants. If civilization required this, civilization would be a failure."

"There is a theory which lias done singular mischief to the cause of general cultivation. It is, that men cannot excel in more things than one; and that if they can, they had better be quiet about it. Man must see things for himself: lie must have bodily work and intellectual work different from his bread-getting work, or he runs the danger of becoming contracted, with a poor mind and a sickly body."

This is the expanded education that man requires for his proper development and happiness; and if heretofore the sciences have not constituted an important part of collegiate instruction in most of our institutions of learning, it has resulted in injury to the professional classes, as well as to the exclusion of the industrial classes from that instruction to which, as men, they had a right.

The tools of the professional classes are words, and their right use has been taught by disciplining the mind in the study of mathematics and literature. Hence our collegiate courses of study have always regarded languages and mathematics as of superior importance to the sciences. The study of the former was not pursued so much for the knowledge of them as for mental discipline, and hence it has passed into an axiom, that, if the student on leaving college forgot his languages and mathematics, but retained his knowledge of words and mental discipline, the chief purposes of his collegiate studies would have been attained. The knowledge of the professional pursuits themselves was acquired subsequently. Professional education, then, consisted of a knowledge of words, and the principles and facts pertaining to law, medicine, or divinity, joined to disciplined faculties of the mind, by which these words, principles, and facts were skilfully used. In all this system of instruction, scientific knowledge formed either no part or an unimportant one. The usual time given to collegiate instruction was too short to allow the study of all, and when the issue was one of conflict, and not of union, an antagonism followed. Heretofore in the progress of the conflict, the long-used course of mathematical and linguistic study has held a supremacy, from the fact that the educated class has naturally adhered to those studies which they themselves had acquired.

But the progress of the sciences has, nevertheless, been uninterrupted as to the few-the savans in science-because of the innate greatness, beauty, and utility of the sciences. They are great and beautiful, for they embody all the laws of nature, and unfold through them the character and purposes of every action in the material world. Man finds himself in intelligent communion with 
everything he is associated with through the senses. He beholds every natural agent actively employed for his good.

This knowledge of the few is rapidly becoming more diffused, and now institutions are being established, having in view the promotion of a "liberal and practical education of the industrial classes in the several pursuits and professions of life." How, then, shall they be successfully established? This is the question to which now the States accepting the donation of Congress are to give a practical answer. Such answer involves two questions for remark-first, what sciences shall be taught? and second, shall they alone, or in comexion with the languages and mathernatics, constitute the course of study?

1. What sciences should be taught? I purpose to give here a general answer only to this question. Under the second and third general divisions of my subject the different sciences will be particularized.

The auswer to this question is determined by the objects intended to be accomplished by the instruction of the industrial classes. And herein lies the great differences which exist in Europe among the agricultural schools, and in the United States among the opinions on industrial education. These agricultural schools have in view but one object, and that is to make the student a good farmer, because in Europe those having political authority do not purpose to make universal the right of suffrage or of holding office. But recently in England, where reform measures point to a more general right of suffrage, able men and members of Parliament demand that the education of the industrial classes shall be commensurate with their duties as citizens. Here there should be but one opinion, and that should demand for every American citizen an education as unlimited as is his sphere of influence. He should be thoroughly imbued with that knowledge which is essential to his occupation. He should be made an influential member in social intercourse, and, therefore, should possess all those accomplishments, such as refinement and strength in conversation, by which caste, both for the individual and his pursuit, are upheld in society. He should wield a ready pen, for the press moulds public opinion; he should be a ready debater, for the "stump" is an instrument of vast political power. He must be made competent, so far as early education is essential, to the holding of every office. In Europe the laborer exercises no direct power in political affairs, but here he governs through representatives directly chosen by himself. Theoretically, the highest offices are open to the poorest citizen: shall he not be fitted for an actual discharge of their duties? Shall he think and act for himself, or shall he be but a mere recorder at the ballot-box of the edicts of parties and of the dictation of politicians? Does this wide-spread government need no steadying influences from the industrial class, whose interests are all identified with peace and stability?

In what I liave to say, then, in reply to the question, What should be the extent of the instruction in the industrial colleges about to be established, I shall not for a moment look upon the industrial man as a mere machine for the doing of certain labor, but shall regard him as an American citizen, and one, too, upon whom, more than on the professional man, must the country rely for that conservative influence over public affairs, which stands opposed to those radical changes which leaders of parties are eternally seeking as a means of their own advancement or occasioned by the mere antagonism of party warfare. If the ordeal through which the land is now passing does not inculcate a lesson of this sort, I confess my inability to understand it. Ambition to rule, or, failing in that, to ruin, led Mr. Jefferson to assert that political heresy, the supremacy of the States, whicli makes them the final judge of what is constitutional; of what is the rightful remedy for an unconstitutional exercise of power, and claims the allegiance of the citizen as due to the State, and not to the national government. Modern politicians of the south but remodeled his party machinery for the same purpose that led to its original invention. Against 
such doctrines, and against their purpose, must be arrayed the honest purpose of the industrial citizen; but to be efficiently so arrayed, he must be endowed with power to curb vaulting ambition; and in this government there is but one legitimate power-that of knowledge.

Government must be administered by occupations, and not by zeal or efficiency in party service, as now; for it is the occupations of society that the legislation of government should most regard, and not those measures enunciated in the platform of parties. Agriculture lies at the base of these occupations. Manufactures, the mechanic arts, commerce, and its aids, as currency, repose upon and exist from it. To legislate for these directly, or from them, indirectly, demands the knowledge of these pursuits. Yet.they are almost unknown in the administration of our government.

Purposing, then, to be the advocate of such an education as will place the industrial classes on a complete equality with the professional, in the discharge of the duties which belong to both alike as citizens of one country, I shall now more directly reply to the question, what sciences should be taught in our industrial colleges?

All instruction relates to two things, the right discharge of duty to ourselves as individuals and as members of the community. Of these in their order:

1. To ourselves. Self-support is the first duty of every person to himself and family. And for this does he follow an occupation. An industrial pursuit, whether on the farm or in the work shop or in the counting-house, demands whatever of knowledge it has as an art. But how much of principle is embodied in this art! Not two crops that I have grown on the farm but demanded a modified culture to meet the ever changing influences of the atmosphere and soil. What is that atmosphere, then? and what that soil? Wherein lies their necessity to plant-life? Who can answer but he who has a knowledge of meteorology, geology, and vegetable physiology? Agriculture has its hundreds of vexed questions in its art unsettled, because individual experiments are apparently contradictory in their results. And they are so simply because those who make them do not perceive the presence of changing influences from season, because they are ignorant of the action that such changes exert on the soil, and vegetable growth; and they cannot perceive it because of their ignorance of these sciences.

And hence, too, the absolute necessity of the experimental farm as a part of these industrial colleges, that what individual farmers cannot determine by experiment, for the reason stated, may be by professors learned in science and and art, and therefore competent to unfold the peculiar elements of growth in every experiment.

Again, let us take the simple act of housing stock in winter as an illustration of the utility of the knowledge of animal physiology. To understand the reason of so doing involves a knowledge of the nature of food, its elements, its digestion, and what digestion is, its assimilation, of the nature of oxygen and carbon, of their union in combustion, how this combustion creates animal heat, what causes exhaust this heat; or, in other words, how food is uselessly consumed when the animal is exposed. To fully understand these demands not only a knowledge of animal physiology, but of chemistry also. It is just as important to have a knowledge of them, if we would understand the reason for cleanliness, regularity in feeding, ventilation, light, \&c. Mere art may often be successful, without a knowledge of the principles upon which it is based, but then it must accept and follow definite rules, and then, as in the unsettled problems in farming alluded to, it gropes blindly, and hence, as in the steps of the blind, its way is devious, its forward course is faltering, being checked by doubts. And this necessarily so because of its ignorance of the nature of the causes operating. 'The prayer of Ajax for light needs to come up from the farm and work shop, as well as from the battle-field. 
The temptation to illustrate the intimate connexion between science and art in many more of the operations of the farm is great; but, then, a volume might be written upon the subject, and usefully too, but a few pages is the necessary limit to me at this time. I must, therefore, content myself with but one more illustration-the utility of deep ploughing.

Many farmers, especially in the west, adhere to shallow ploughing, because they have produced many good crops firom it. 'They know that fact, but, for want of chemical and meteorological knowledge, they do not perceive the reasonthat it is applicable to new lands only; and, therefore, when the lands have become worn, their failures are charged to that which is not a fact, the alleged change in the seasons since their more youthful days.

But let the farmer, when burning his log-piles, follow the carbonic gas, which contains the wood and oxygen, united by the combustion, to its absorption by the blades of grass, but especially by the soil, more particularly when it is rich in humus, by which the absorbent power of the soil for the gases is so largely increased, and he will then perceive the vast amount of this element of vegetable growth which is taken into the soil through the atmosphere. Now in proportion as the air can circulate in contact with the particles of the soil, so will be its deposit of carbonic acid. Deep ploughing and a well-pulverized soil act as a manuring, and hence the principle of the naked fallow. But when lands are new the lower soil is loose, and carbon exists in it largely from decaying roots. Good crops are made at the expense of this carbon, and not because of shallow ploughing. And then, too, the air can reach a greater depth than when the under-soil, by pressure of the plough and the weight of stock, becomes more compact. Is it not obvious that we must know the causes of things? and to have this knowledge the sciences must be studied.

Again, to the farmer is given dominion over the animals of the farm, as well as its soil and atmosphere. Animals are so made as to be his dependents, and he theirs. To subserve the purposes of this relation, the Creator has endowed them with mental properties in unison with it, and to man has been given the power to discover these properties, and so use them as to receive the full benefit of this relation. - Does the Creator require the lash as the instrument of instruction to the horse? Has the All-wise made the exercise of brute force on man's part an element of his dominion over it? Far from this is the trutb. He has implanted within it strong attachments and an implicit obedience to superior power. Rarey was not less strongly attached to the horse, and this led to an association with it so kindly, that this attachment, more than abstract reasoning, revealed to hin the true management of the horse. 'The use of a thing, whether animate or inanimate, according to the inherent laws of its organization, is the ouly rule upon which a correct art can be founded. It is the object of every science to unfold these inherent laws. Psychology, therefore, is a study necessary to the farmer, as also comparative anatomy.

It must be remembered that the donation of Congress is not limited to the instruction of agriculturists alone, but embraces all industrial pursuits; hence the manufacturer, the mechanic, and the merchant should be taught such branches as will best aid their respective pursuits. Some like references to these studies, therefore, is necessary.

Manufactures embrace so large a field of industrial activity and enterprise that they demand business qualities and attainments of the highest order. The purchase of the raw material and the sale of the commodities manufactured require a mercantile education; and in the management of inachinery, and of the daily processes of its production, a knowledge of physics, which treats of the laws of forces. Economy must be strictly observed, for such is the competition of manufacture, that an establishment operating by machinery that is less economical than another soon results in loss. The history of manufactures abounds in incidents accomplishing great economy, as the hot-blast superseding the cold- 
blast in smelting iron. It is unnecessary to particularize any one of the ten thousand improvements which inventive genius lias given to all the machinery engaged in manufactured production. They all show that labor-saving economy was demanding a cheaper product, that it might the better compete with its rivals. And this competition must ever continue to demand the highest skill and greatest prudence in every act of the manufacturer, from the purchase of the raw material to the sale of the articles made from it. Whilst it is true that the mere operator may, in many cases, successfully conduct his business without a thorough knowledge of the principles involved in the machinery he uses, yet such are not among the lofty names that honor the inventive genius of our land. They are not those who have cheapened commodities nor created new ones: they can use a steam-engine, but have not improved it: it required a Eulton to apply it to navigation. The locomotive, nor the daguerrotype, nor the telegraph, nor chain and tubular bridges would have been invented by one ignorant of the principles which these and like inventions represent. These principles are greater or less, more complex or simple; if the few may be great in their application, all should know the more simple principles. If it required an Ericsson to create the impenetrable iron-clad, nevertheless the more useful mower and reaper spring from the more readily perceived mechanical powers.

Shall it be said that even education cannot make all inventors or successful manufacturers? I answer, nor has it made every lawyer a Webster, nor every physician an Astley Cooper, nor every preacher a Beecher. Still, education is a leaven, which, pervading the entire mass, fits it for a higher destiny, and the individual for greater success, because, seeing clearly the principles of his occupation, he pursues it more enthusiastically. As well allege that the sun is useless, because we may travel by star-light. Why, said a boy to me when we were crossing a chain-bridge of immense strength, do they require a regiment when crossing it to break their step? Shall an American manufacturer or mechanic be less interested in the reason of things than this boy?

Of the utility of instruction to the merchant to fit him for success in his occupation, or of the studies he should pursue, it is unnecessary now to speak, or even to give a single illustration, because the commercial colleges springing up in every city attest their advantages.

Having considered the necessity of knowledge to the individual in that occupation he follows for his own and his family's support, I wish to ask the reflecting mind to accompany me in what I may briefly say of its necessity in the right discharge of his duty as husband and parent.

The Anglo-Saxon is justly regarded as the noblest element in the English and American descent. And it is so for the reason that, in its entire history, it has more highly regarded the family in its social and political relations. But has it, and do we now, give the family all the regard it demands?

The present time in agricultural affairs is distinguished by its study and practical application of the principles of breeding. The power of these principles, when rightly directed, is seen in our Virginia and Kentucky blooded horses, in the short-horn and other breeds of cattle, in sheep and hogs. They show that both physical-and mental characteristics are subject to these principles. Cease to regard them, and at once deterioration begins. Now man is as these farm stocks - an animal, subject to inprovement or decay, both in body and mind according as regard is paid to the principles of his mental and physical propagation. With what care does the skilful stock-grower take every step; how he balances the qualities that may coalesce, or those that may be antagonistical. But in that noblest of all creatures, man, low entirely is every rule of his reproduction overlooked. Poets sing of oneness of soul, of the blending of hearts; and the universal attraction that the subject of love has over allthe young and old, the taught and untaught, but attests its bearing on our welfare. 'The right-thinking and right-feeling mind ever owns its greatness, 
and that poet, like Schiller, who ascribes to it the highest and noblest influences, is the most honored. Nevertheless, the ancieuts personated love as a blind deity. In forming our marriage relations low few are governed by any one of those considerations which has regard to the character of our children. Hence the fact that great minds do not reappear in the children of those gifted with them. This gift is an accident; an accidental coming together of two fine minds ; and only where these harmonize is there a perpetuation of them in the offspring.

An exemplification of the power of these rules of descent is seen in the Jewish people. Originally of peculiar and rather limited mental powers, by the " in-and-in breeding" as it is called, they have so perpetuated these peculiarities that to-day the Jew is precisely the same being he was in the time of our Saviour; and so he will continue until he intermarries with people of other nations. 'Then only his mental and physical traits will be changed.

But the transmission of physical qualities is of not less importance than the mental. 'The list of inheritable diseases is frightful; in my judgment, based on long observation, there is not a chronic complaint but is inheritable. And who knows a woman so complete in health as to be free from them? Fashion, in past years, has ruled the sex to so great a destruction of their constitutions, that everywhere, in the country as in the town, there is a universal ill-health. And as to men, it is conceded that the population of the cities would soon decrease were it not for the renewed sources of health that flow into them from the country. Wherefore, then, these deplorable evils?

There can be but a single answer. Ignorant of themselves, for want of the study of physiology, nearly every law of health is disregarded. 'They are overlooked in the marriage union, in the treatment of childhood, in our systems of education, and in the business of life. In early years the child is dressed with sole reference to its appearance, and the glorious sunbeam of so great chemical power over vegetable life, and not less essential to animal development, is sedulously kept from it, lest a tan or a freckle might stain the blanched skin. To economize fuel, our houses are constructed to exclude fresh air, and our food is selected more to please the palate than its adaptation to digestion and the wants of the body. It is eaten with the liaste business demands, and not as the nature of digestion requires. Thus whilst the nervous system is exhausted by excessive mental application, the blood system which should sustain it, is poisoned in the food and digestion by which it slould be sustained.

Do our systems of education fit us for the weighty obligations arrising from the family relation? I may be told that physiology is now made a school-book. True, but in what way? That which most concerns this relation is excluded. The vital organs are described, but their offices, their mutual sympathies, their relations to the brain and mind, their action in lealth and their condition in disease-that is to say, physiology as a practical good, to direct us in all that relates to the body and its relation to the mind, finds no place in our educational courses.

Again, upon the mother devolves the first instruction of childhood. Objects are early noticed, and their nature and relation to the infant learned by it. 'The mother should instruct in these : those about the house, those beyond it, in the gardens and fields and woodlands. But who ever saw a mother out in the open air thus teaching childhood, instilling a love for the beautiful from the flowers and green grass and leafy trees? from the azure sky, or the soft, gentle winds or the dark-rolling, tempestuous cloud? At an early age, to get the clild "out of her way," it is placed in school, to learn abstract ideas from books and a teacher as little competent as the mother to understand its nature and wants.

In these errors and defects there are placed before us those studies that should fit the individual for the right discharge of the duties resting upon lim from the family relation. 'They are physiology, psychology, and phrenology, the education of the family, \&c. 
2. Knowledge as members of society.-The second division under the general question, What studies should be taught? relates to the right discharge of the duties of the individual as a member of the community. 'These duties place man in two connexions-in social intercourse, with those immediately around him; and in the discharge of the duties of citizenship, to the political institutions of his country. But they need not be considered separately, for the acquirements that fit him for the one are demanded by the other. He must have general knowledge, to exercise influence in society, and political information, to act well his part as a citizen; and the agencies for using these are, good conversational qualities, and readiness and elegance as a writer and speaker. Of these - agencies-for I shall speak of them first -is a knowledge of language

In advocating the study of, at least, the Latin in the.industrial universities, I caunot but regret to differ from Mr. Herbert Spencer, whose opinions on education should have an unlimited sway. Concurring with him in all that he has written on the necessity of the study of science, in his admirable work on education, yet I cannot approve of the disparagement of the languages contained in the latter portion of the following paragraph:

"Paraphrasing an eastern fable, we may say that in the family of knowledges, Science is the household drudge, who in obscurity hides unrecognized perfections. To her has been committed all the work; by her skill, intelligence, and devotion have all the conveniences and gratifications been obtained; and, while ceaselessly occupied ministering to the rest, she has been kept in the background, that her haughty sisters might flaunt their fripperies in tlie eyes of the world. 'The parallel holds yet further. For we are fast coming to the dénouement when the positions will be changed, and while these haughty sisters sink into merited neglect, science, proclaimed as highest alike in worth and beauty, will reign supreme."

What is meant by the term "hanghty sisters" is the languages and mathematics, and the prediction that they "will sink into merited neglect" is a condemnation of their utility. The figure he uses is a just one: they are sisters of a common household, and the unjust degradation of one is no cause for her exaltation by the debasement of the rest. They are sisters, and should live in sisterly equality and affection, each fulfilling the purposes of her existence.

"Words are things." And in this country especially, where thought clothed in words acts on mind, they are things of great significance. It was a few written words of Mr. Jefferson that created the doctrine of State rights, claiming supremacy for a State and its right of nullification. It was words, printed and spoken, that gave these other words a power to create this rebellion. Words are a deadly poison or a most nutritious food, according as they are compounded and administered. Mr. Jefferson made them this poison; the Apostles, by them, offered eternal life. It needs the aid of language to entice to. the study of science. Words may repulsively ask to this study, or invitingly draw to it. They can embellish every fact and thought. To say, then, that an agency so powerful for good or evil should sink into merited neglect is an unjust opinion, the incorrectness of which is shown by Mr. Spencer's use of words in every page of his masterly writings. But it is an opinion induced by that repellant antagonism, which, like the pendulum, swings from one extreme to its opposite. It is an instance of that "rhythmical tendency," as Mr. Spencer terms it, that carries us from "one absurd extreme to the opposite one"-a reaction, "carried as reactions usually are, somewhat too far." This antagonism leads to one-ideaism. To a certain extent, this over-valuing one subject by underrating all others, gives energy in our advocacy of it; but, nevertheless, it is a vice, often tending to insanity in zeal, as it frequently does to aberration of mind, as seen in the monomaniac. The moral of the story of the Knight of La Mancha should not be forgotten. In the vindication of the utility of the sciences, many of their advocates have been carried beyond a 
proper degree of opposition against their unjust neglect, and have become as unjust in their denunciations of the languages.

If words, then, are things, a knowledge of them should not be disregarded in a government like ours. It is very true that to the professional classes languages may be more important, because words are an important part of their occupations, as well as in their relations to social influences and their duties as citizens. It is also true that the farmer is more isolated than others, but for that reason he should be more skilled with the pen. Either through the agency of the press or by letters he should communicate with his fellowfarmers on matters of their occupation. All of them should take counsel together on public affairs. But all other of the industrial classes are in constant association. Without the knowledge of words and their ready use, the industrial classes can never wield an influence for the defence of their occupations, or their social status, or for the right administration of public affairs. As a mere accomplishment they have a right to it, for social power rests much on accomplishments; and whatever adorns, as well as whatever strengthens and elevates, belongs as much to the industrial classes as to the professional. He is false to them who demands less. The study of a language such as the Latin is the readiest way to a correct understanding of the English language, for it has given to it a third of its words in common use, and names to much of the nomenclature of the sciences. It lays, too, the foundatiun for a more speedy acquisition of most of the modern languages. Of the latter, it is a prevailing opinion that French and German shouid be taught in the industrial colleges, not as a necessary part of the regular course of instruction, but to those who may desire to better prepare themselves for commercial transactions among the foreign population at home, or with foreigners abroad, as "well as to all others wishing such instruction from any motive.

Of those studies which may be classed among the accomplishments, I will refer to but two-history and biography. The history of nations must be studied by the industrial classes, but not that history whose only purpose is to narrate what kings and parties have done, or what battle has been fought by this or that general. 'They have a history of their own, and therefore history should narrate what has been accomplished by the industrial classes. It should show, as Mr. Herbert Spencer remarks, "to what extent the division of labor was carried; what influences regulated production; what was the connexion between capital and labor, between employers and employed; what were the agencies for distributing commodities; what were the means of communication; what was the circulating medium. Accompanying all of which should come an account of the industrial arts technically considered, stating the processes in use and the quality of the products. Further, the intellectual condition of the nation in its various grades sliould be depicted, not only with respect to the kind and amount of education, but with respect to the progress made in science, and the prevailing manner of thinking. The degree of æsthetic culture, as displayed in architecture, sculpture, painting, dress, music, poetry, and fiction, should be described; nor should there be omitted a sketch of the daily lives of the people, their food, their homes, and their amusements ; and lastly, to connect the whole, should be exhibited the morals, theoretical and practical, of all classes, as indicated in their laws, habits, proverbs, and deeds. All these facts, given with as much brevity as consists with clearness and accuracy, should be so grouped and arranged that they may be comprehended in their assembled connexion, and thus may be contemplated as mutually dependent parts of one great whole;" or, in other words, that the listory of the industrial classes should be written and studied, and not the acts of kings and potentates.

Biography should be read; not that of party rulers, but of those who were leaders in invention; of those whose ships whitened every ocean, who reared 
up manufactories, who mined from the deep earth its coals and minerals; of those who started on its unending track the locomotive, and made the ship

"Against the wind, against the tide,

To steady with an upright keel."

Let history and biography be so written, and their study will serve to elevate the industrial classes in their own estimation, and make them true to themselves; and being so in their political relations, they will be false to no duty; as they have been in times past, to themselves and to the country, save in the ready sacrifice of life to defend it in the field against leaders not of their class and pursuit. Then the theory of our government, that the humblest citizen may attain the highest offices, will be a reality in this, that he can do so through the pursuit of that industrial occupation which lras had its just weight in determining political power. Eminence in that occupation, joined to the enlarged and liberal mind which the education of the industrial colleges should give, will render illustrious, as was Cincinnatus when called from the plough to save Rome, or as was Washington, in whom the surveyor's chain brought out qualities that raised him to the highest military command.

There remains but one more matter of general remark. We have seen how parallel run the social and public duties of allclasses in the community. Whatever studies are essential to disciplining the mind of the professional man, are they not as important to the industrial man? 'The power to think, and to apply thought, is indeed more necessary in the inventions, in finance, and in the more extensive coinmercial pursuits, than in the professional. Those destined to follow the mechanic arts must study mathematics. 'The commercial pursuits demand a knowledge of political economy. What, then, prevents those destined for professional.occupations from acquiring in these industrial colleges the instruction they need? Are not the sciences the best of all branches of study for them?

By the preacher the study of science can no longer be disregarded, for that exalted feeling which is poetry or religion, according as it is produced by a contemplation of the works of nature, or of the wisdom of nature's God, becomes still higher and more intense when science reveals the infinitude of that wisdom. "Whoever," say a writer, "will dip into Hugh Miller's works on geology, or read Mr. Lewis's Sea-side Studies, will perceive that science excites poetry rather than extinguishes it; and whoever will contemplate the life of Goethe will see that the poet and the man of science can coexist in equal activity. Is it not, indeed, an absurd and almost a sacrilegious belief, that the more a man studies nature the less he reveres it? T'hink you that a drop of water, which to the common eye is but a drop of water, loses anything in the eye of the physicist, who knows that its elements are held together by a force which, if suddenly liberated, would produce a flash of lightning? Think you that what is carelessly looked upon by the uninitiated as a mere snow-flake does not suggest higher associations to one who has seen through a microscope the wonderfully varied and elegant forms of snow-crystal? Think you that the rounded rock, marked witl parallel scratches, calls up as much poetry in an ignorant mind as in the mind of a geologist, who knows that over this rock a glacier slid a million years ago? 'The truth is, that those who have never entered upon scientific pursuits know not a tithe of the poetry by which they are surrounded. Whocver has not in youth collected plants and insects, knows not half the halo of interest which lanes and hedgerows can assume. Whoever has not sought for fossils, has little idea of the poetical associations that surround the places where imbedded treasures were found. Whoever, at the sea-side, has not a microscope and aquarium, has yet to learn what the highest pleasures of the sea-side are. Sad indeed is it to see how men occupy themselves with trivialities, and are indifferent to the grandest phenomena; care not to understand the 
architecture of the heavens, but are deeply interested in some contemptible controversy about the intrigues of Mary Queen of Scotts; are learnedly critical over a Greek ode, and pass by, without a glance, that grand epic written by the finger of God upon the strata of the earth!"

And who can look out on the ocean through Maury's Physical Gengraphy of the Sea, or contemplate, through the microscope, that infinitude of life which lies beyond the reach of unaided vision, but which fills up the depths of the ocean with active and joyful existences, or can follow its unceasing evaporations in their varied forms as they pass over the dry lands, enriching and beautifying them with descending rains, and not perceive the grandeur of the Psalmist's exclamation, "The sea is His, and He made it?" Shall the pulpit longer continue in ignorance of science, as if the God of nature and of revelation were of antagonistical attributes? Does a study of polemical theology more enlarge human sympathies than a knowledge of the wisdom and love of the Creator, as seen in his works?

To the lawyer, a knowledge of the sciences is still more essential. For what better mental discipline to him than the knowledge of the steps adopted to discover and unfold scientific truth? It is as raluable to him to determine the differences between error and truth, or crime and innocence, in liuman conduct. It not only disciplines his perceptive faculties in seeing the relation of one fact to another, but strengthens his judgment in determining the consequences of that relation. As the study of natural laws demands complete investigation, surely the power to make it must be, to the legal mind, one of its strongest acquisitions; for it can search into the elements of human conduct, into motives as developed by acts; it can trace the secret steps in the commission of crime through the motive. The same mental discipline is as essential in such investigations as to the naturalist who deduces the structure and habits of a fish, that now has no other existence than a fossil scale. The reasoning processes are the same in determining moral relations as in the physical; for both perceive and determine the fitness of things. The logic in the demonstration of a moral truth, or a legal proposition, or a geometrical problem is the same as used in determining an extinct animal from a single fossil remain.

But the study of science adorns the mind with the noblest illustrations a lawyer could use to develop or strengthen his arguments. For as much above as are the laws of nature those of man, so much loftier are they as means of comparison. Just as the beau-ideal of the orator, which Cicero had always before him, aided him to attain his own greatness in oratory, because of its superiority to himself as an orator.

The bar and the pulpit, in their want of illustrations and comparisons drawn from the sciences, show that neglect of their study which has so long existed in our educational institutions. 'This neglect the sciences are now avenging; for, in their recent great development, they have lessened the supremacy of both the lawyer and the preacher, especially in social influences, by exhibiting their ignorance of subjects the most attractive and instructive in social intercourse. The educational acquirements of both are becoming fossilized: they are dead, not living, as are those of the man of science.

"At present," says the author of Friends in Council, "many a man who is versed in Greek metre, and afterwards full of law reports, is clildishly ignorant of nature. Let him walk with an intelligent child for a morning, and the child will ask him a hundred questions about sun, moon, stars, plants, birds, building, farming, and the like, to which he can give very sorry answers, if any; or, at the best, he has but a second-hand acquaintance with nature. Man's conceits are his main knowledge. Whereas, if he had any pursuit connected with nature, all nature is in harmony with it, and is brought into his presence by it."

If, then, the preacher and the lawyer should not be ignorant of the sciences, and 
the industrial classes should study language and mathematics, for what purpose should separate institutions of learning be maintained for them?

This question is the more significant when we consider how very few of our collegiate institutions are prepared to give proper instruction in the sciences. With the exception of these few-the oldest and richest of the eastern Statesthey have no museum at all, and the united apparatus of the entire colleges, in many of the western States, would be insufficient for a single industrial school. The sciences, as Mr. Owen shows, must be tanght through the medium of the eye, if a love for scientific instruction is to be spread abroad through all classes and pursuits. To procure such museum and other things essential to an industrial college, will require an expenditure that will demand, not only what can be derived from a united fund, but arlditions to it by legislative grant. Mr. Owen shows this.

And if so. what can be accomplished but the destruction of the fund, by creating two or more institutions in each State, or parcelling it out to several existing colleges, that a like corps of professorships may be established in each one of them? And this, too, when the condition of our few agricultural colleges shows that, so far, they have been unable to obtain a patronage from the industrial classes sufficient to sustain any one of them. 'T'ruly, to divide is to fall. As wisely may we contend for a division of these United States.

Since this article was in type, I have received the catalogue of the Michigan State Agricultural College for 1864. This is one of the best endowed and most successful of our agricultural schools. It has a farm of 676 acres, of which 275 are under cultivation, and seven professors, with a superintendent of the farm. It is located in a central position of our great northwestern agriculture, among a population zealous in the cause of education, and in a State where common schools are most successful. Here, if any where, a strictly agricultural college could find support, yet the catalogue shows but sixty-two students in attendance this year, three of whom have been expelled. Of the fifty-nine left, thirtythree are in the preparatory class, leaving but twenty-six; for the senior, sophomore, freshman, and select course classes. There seems to be no junior class. If the number of students is a proper criterion, then this Agricultural College is a failure. It is an agricultural school exclusively.

The State Agricultural College of Pennsylvania is not more prosperous. If this is the result in such agricultural States, what will be the success of like colleges in eastern States, whose agriculture is so much less, in proportion to the population? 'These facts but the more confirm me in the views above expressed, that whilst our Industrial Colleges should have especially in view the thorough education of the industrial classes-not farmers alone, but the mechanic, the manufacturer, and the merchant, too-their course of instruction should be such as to provide also for those purposing to follow professional avocations.

\section{PART II.}

Having considered in Part I, in a very general way, the nature of the instruction that should be given in the industrial colleges, from the objects it should seek to accomplish, I am now to examine, in Part II, the several kinds of industrial colleges and their courses of instruction. What $I$ have to say in regard to them is taken chiefly from Mr. Flint's report to the Massachusetts State Board of Agriculture, and the report upon the plan for the organization of colleges for agriculture and the mechanic arts, by the late Dr. E. Pugh, president of the Agricultural College of Pennsylvania.

However different in extent are their courses of instruction, the several institutions referred to in these reports can be regarded in a fourfold classification: 1st. Where the agricultural institute or school is a part of a university. $2 \mathrm{~d}$. 
Where, although separate from it, the languages and mathematics are a part of the course of instruction. $3 \mathrm{~d}$. Where the sciences only are taught. In all these practical instruction on the experimental farm and in the propagating garden and workshops is given. A fourth kind is where this practical instruction is not given, but theory alone is taught, and this by lectures only, to the exclusion of text-books.

It is my object, in this division, to set forth the character of each of these classes, as seen in European schools, and in the plans advocated here.

1. The university plan.-The recent excellent and most timely publication of Mr. Flint, of the Massachusetts State Board of Agriculture, makes us better acquainted with European agricultural schools than we have been heretofore. "These," he says, "are of two kinds: those which are connected directly or indirectly with universities, and those which are independent of other institutions." Prominent among the first kind is the Agricultural Institute at Jena, in Saxe-Weimer. It is a part of the university at Jena; but whilst it has a course of instruction of its own, the special purpose of which is to prepare the student for agricultural pursuits, he may avail himself of all the advantages which a more thorough instruction in the principles of any science in the university course can give him. The influence of this arrangement, both on the course of studies of the institute and on the emulation of the student of agriculture, is thus referred to by Mr. Flint: "In consequence of the use of these means of instruction, the institute stands in an independent relation with the university, which secures it great advantages; yet far more important is the more intimate connexion with it; that is, the necessity that its instruction of the same principles should be more general and comprehensive, and fundamentally scientific, like that of the university." And this necessity is made practically greater by infusing a loftier ambition among the students of the institute to emulate the thorough instruction imparted in the university.

As so little lias yet been laid before the American farmer of the studies in these schools, it may be useful to give here the character of the instruction at this institute. Mr. Flint says: "The sciences useful to the farmer which the institute teaches are as follows:

1. "Sciences relating to the branches of agriculture.-Sciences bearing on the cultivation of agricultural plants, in its whole range, as climate, soils, cultivation, tillage, manuring, seed, after-culture, harvesting, culture of grains, mercantile and fodder plants, fruits, \&c. The breeding of animals, in its whole range, the principles of breeding, nourishment and care, raising, keeping and use of partic ular sorts and races of domestic animals; farm management, with all its branches, book-keeping, valuation, \&c.; agricultural excursions, demonstrations, and conversations.

2. "Fundamental and auxiliary sciences of agriculture.-National economy, agricultural history and statistics, agricultural law, physics, meteorology, general cliemistry, agricultural chemistry, practice in the laboratory, qualitative analysis, quantitative demonstration of agricultural materials, grains, oil fruits, guano, other kinds of manures, soils, plant ashes, mineralogy and geognosy, including knowledge and classification of soils. Botany, with special reference to the physiology of plants; including botanical excursions, instructions in forestry, care and use of woodland. Gardening. Zoölogy, with special reference to knowledge of insects, veterinary science, anatomy and physiology of domestic animals on the farm; patholngy and therapeutics, chirurgery, shoeing, \&c. Mechanics and machinery, agricultural machinery and implements, their construction and use. Agricultural technology, including technological excursions, bread-making, manufacture of vinegar, distilling, brewing, sugar-making. Geodosy, use of the surveyor's chain and theodolite, field measuring, levelling, agricultural mechanics." 
As aids to imparting the instruction embraced in the above subjects, the institute has-

1. "A farm of about 1,400 acres, with a numerous herd of cattle, a distillery, brewery, and silk-raising establishment, which serve as a means of illustration;

2. "An agricultural botanic garden, attached to the botanic garden of the university;

3. "A well-appointed chemical laboratory, with a sufficient number of convenient working desks;

4. "Collections of minerals and earths, dried plants and seeds, models of fruits, collections of insects, technical apparatus, so far as requisite for reference in the lectures ;

5. "A valuable agricultural library for the use of the students;

6. "A reading-room where all the agricultural papers are taken;

7. "An infirmary for sick animals, with a room for operations and necessary tools;

8. "A rich collection of pathological preparations and objects.

"For the ancient and modern languages, and the fine arts, the university," says Mr. Flint, "offers extraordinary opportunities to those who desire them."

This institute has eleven professors, and but 110 students, being but ten students to each professor. This fact appears singular to us, and might be attributed to some special cause, was it not characteristic of all European agricultural schools. At the still more celebrated school of Hohenheim, near Stuttgardt, in Wurtemberg, there are but 161 students. At the not less celebrated one of Grignon, near Paris, in France, but 75; and the English agricultural school of Cirencester, at Gloucester, has proved a failure. These attendances, so meagre, admonish us that the successful establishment of agricultural colleges is a difficult work, and that we must clearly understand the adverse influences they have to encounter before we endeavor to establish our own. We shall recur to this matter presently.

II. Agricultural institutions, separate from universities, but giving linguistic and mathematical instruction.-An institution of this kind is brought to our notice in the excellent report of the late Dr. E. Pugh, president of the Agricultural College of Pennsylvania. He passed six years in Europe studying its agricultural schools, and the opinions of one thus qualified to advise will have their weight with all. The number of professors recommended by him for an industrial college of the highest character is suxteen, including the president. 'The professorships relating to the sciences are as follows: 1, of pure chemistry; 2, of agricultural chemistry and geology; 3, of metallurgy, mining, and mineralogy, and chemical technology; 4 , of anatomy, physiology, and veterinary; 5 , of natural history, more particularly of zoölogy, comparative anatomy, and entomology; 6, of botany, horticulture, and entomology.

'T'o these he adds the following, relating to languages, mathematics, and the practical arts of agriculture and military affairs :

7 , of pure mathematics and the higher mechanics and astronomy; 8, of civil engineering and applied mathematics; 9, of natural philosophy and astronomy, mechanics and physics; 10, of English language and literature; 11, of modern languages, particularly German and French; 12, of practical agriculture; 13, of military art and science, and teacher of military tactics.

To the foregoing, he says, should be added the following, though not indispensable to a system of industrial education :

14, of Latin and Greek languages and literature.

Numerous as these professorships may appear to be, yet they are all essential to an industrial college, and no one of the enumerated studies can properly be dispensed with. On the contrary, there should be added to them meteorology and physical geography, both of the land and sea, for these studies embrace the all-important subjects to the farmer of the distribution of heat and moisture. 
On the nineteenth, twentieth, and twenty-first pages of his report, Mr. Pugh speaks of the apparatus and natural history collections and museums essential to the proper instruction in each study. But we omit referring specially to what he regards as necessary, for Mr. Owen fully sets it forth in his communication.

III. Agricultural schools, without instruction in languages and mathematics.Whilst these do not teach either modern or ancient languages, and pure mathematics, they yet adopt a scientific course, greater or less in different institutions, but their chief object is a practical instruction, having reference to such preparation of the student as will qualify him for the superintendence of a farm.

Among the first of such schools in Europe is that of Hohenheim, and to it $\mathrm{Mr}$. Flint appears to have given much attention. In the theory of agriculture it requires but two hours each day of instruction, and the sciences do not appear to be taught to any great extent. Stock-raising is one of the highest importance connected with it, aud to its general practical course of instruction it has added several special ones, among which are gardening, fruit, silk, and bee culture, distilling, natural economy, and manufacture of agricultural implements.

It has an experimental field, and as this feature of its instruction is admirably adapted to the improvement of American agriculture, we quote what Mr. Flint says of it:

'The experimental ficld was designed, not only as a means of instruction for the students, but also as a means of investigation on the part of the professors. For this purpose the plots appropriated to each experiment consist of nearly a quarter of an acre each-a size sufficient to give to each a fair and full trial in management, manuring, cost of culture, results, \&c. The fact that there are ninety-six of these plots indicates that this part of the enterprise receives its due share of attention. It also offers the means of raising a great variety of seeds which supply the wants of the farm, and form an important item in the receipts of the institute, WHILE IT SECURES TO THE FARMERS OF THE COUNTRY

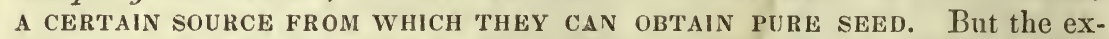
periments on the farm are not wholly confined to this field. Among those that have been tried the following may be mentioned:

1. Upon the transmission of caries in grain, and the influence of washing, soaking, fermentation of the seed on the stock, as well as on the age and change of seed.

2. Observations on the sensitiveness of growing plants to frost.

3. On the effect of large, middle-sized, and small seed potatoes.

4. On plucking off the blossoms of potatoes.

5. On the exhaustion of land by rape culture. [Here it slould be by tobacco and corn culture.]

6. On the exhaustion of wheat, in comparison with green plants, and fallow.

7. On the culture, year after year, of beets on the same land by constantly fresh manuring. [Here it should be of all our crops, especially of cotton, sugarcare, corn, tobacco, potatoes, \&c., requiring summer cultivation, in comparison with crops sown in the fall, as wheat, barley, and rye, both with and without manuring.]

8. On the continued culture of artichokes on the same land, with manuring every three yearg.

9. On the effect of mowing, or not mowing, the late clover stubble in autumn. [The second crop we suppose is here meant.]

10. On depasturing of winter barley.

11. On the manuring of meadows.

12. On manuring with Poruvian, Baker's Island, and fish guanos, rape-meal, bone-meal, superphosphate, Chili saltpetre, salt, gypsum, gas lime, soda, peat, ashes, Liebig's patent manure. artificial manures. 
13. On the effect of fresh and rotted manure, the mixture of various crops, and many others.

This field, says Mr. Flint, was very instructive and interesting.

Speaking of the botanic gardens of this institute, he says :

"I spent a good deal of time in the various parts of this garden. It is laid out on a generous scale, with an agreeable park-like aspect; groups of trees, ornamental and useful shrubs, parterres of flowers, and lawns well kept. A part of it is devoted to annuals, where an immense number of varieties of wheat and other grains are cultivated; each plot labelled, so that the visitor may know, without a guide, what each contains. In another part are the perennials, especially those of economical value. The grass garden forms a part by itself, where the different species of grass are cultivated in little clumps, each labelled with its scientific and common name, while an arboretum of considerable extent is at all times accessible for students and others."

Course of instruction, museum, library, \&c.-These do not radically differ from those of the institute at Jena, and therefore need not be particularized; but during the working weather there is too much work, and not enough of study. Ten hours a day of labor, what, at least, an American farmer would call by that name, is too exhausting to allow profitable study. Mr. Flint thus speaks of the instruction on the practical farm of Hohenheim:

"The students in the school of practical farming have a lecture from 5 to 6 0 'clock in the morning, then work from 7 to $11 \frac{1}{2}$, and from 1 to $6 \frac{1}{2}$ or 7 . They have another lecture or study from $\delta$ to 9 o'clock. 'The time devoted to study and instruction is increased in winter and during rainy days. They are the sons of peasants well off in the world, having enough to rent or buy a farm. They enter for three years, and are not admitted for a less term."

IV. Institutions discarding the languages, mathematics, and also manual labor.-It is hardly necessary to take any notice of these institutions. They have assumed $n o$ prominence in Europe, and the only one referred to by $\mathrm{Mr}$. Flint is the institute at Geisberg, near Weisbaden, in the duchy of Nassau. "It is intended," says Mr. Flint, "for the instruction of practical farmers, without teaching practice on the place. It was founded in $1 \mathrm{~S} 35$, and on the principle that it is of no use to teach the theory and practice at the same school. There is a small farm connected with the school, but, judging from the helterskelter or generally mixed-up condition of everything about the premises, I should think they were quite right in not attempting to teach practice there. Old ploughs, drays, carts, harrows, and everything, else lay around the buildings in no small confusion. When I drove into the yard I felt sure we had made some mistake, and had got upon the premises of a very slovenly farmer.

"The theoretical instruction is given in a regular course of two winters. During the intervening summer the students are either at home, at work on the farm, or, if they desire it, the director of the institute procures them suitable places with skilful practical farmers.

"The instruction is given by lectures, and written and verbal questions on the studies."

A plan of instruction, like that of this institute, which ignores text-books and practical agriculture, the experimental garden and field, and practical instruction in stock-raising, possesses but little power to successfully communicate even theoretical knowledge only.

Having noticed the most leading features of these different plans, before leaving them it may be useful to point out some matters of a minor character, but which are still useful.

1. The general mode of communicating practical instruction.-On this subject we quote Mr. Flint's notice of that pursued at the institute at Grignon, in France:

"'The pupils are required to work four hours a day, and are successively charged with different service on the farm, which they are called upon to observe 
daily. They assist from four and a half in the morning in the order of work which the director gives to the different chiefs, and in the evening they assist in the daily reports which are given in to the director, and in entering upon the books the reports upon all the operations of the farm. The labors which they perform are various. They comprise the cultivation, the care of animals, the manufactories, the permanent improvements, building of roads, the care of the forests, the gardens, \&c. They attend, during the visits of the veterinary surgeon, in the cattle stalls; they curry the cattle and horses; and perform various operations under the directions of the heads of the various branches. Each pupil is obliged to make a detailed report to the director upon the work he performs, and is allowed to make any suggestions he may see fit, which are accepted and acted on when practicable.

"This constitutes the practical part of their education. Two are appointed as general inspectors under the orders of the director, and the duties alternate; that is, a certain number has charge of one department for a certain length of time, say a week or a month, and then they are assigned to another department in succession; as, for instance, four may be charged with the management of the oxen, two with that of the horses, two with the pigs, two with the sheep, two with the poultry, four with the silk-worm establishment, forming thus a sort of committee on each branch, the duty of which is to see that the proper attention is paid to all the details; as among stock, to see that it is properly fed, to note the results of any changes of feed, \&c. So, too, with the garden, two or more are appointed; two on woods and plantations, two to inspect the repairs and improvements going on, two on the manufacture of starch, cheese, and other manufactured products, two on book-keeping and accounts, \&c.

"I believe the practice is to have one of the two on each committee of two years' standing, and the other a newly-entered pupil. At the end of the week all are required to make a report in the presence of the whole school, when the professor comments or enlarges upon the various operations going on, and gives such additional information as may be suggested by the facts presented. In addition to this exercise, which has the effect to train the young men in the art of composition and the skilful use of language, as well as to keep them informed of the working of the whole system, the professor takes the classes to see the various operations of the farm, pointing out the most approved method of performing them, \&c. He lectures thus on the different practical processes of farming at the seasons when they actually take place.

"Each professor, in his own department, moreover, is expected to give his instruction a practical turn, by means of short excursions, botanical, geological, \&c."

2. Excursions.-The excursions just referred to seem to be a part of the systems of all the agricultural educational institutions of Europe. Of the school at Schleissheim Mr. Flint says:

"Excursions are also made to neighboring estates for the purpose of observation, the results of which are written out by the pupils. Money is sometimes appropriated by the government to defray the expenses of long excursions."

Of the institute of Weihenstephan, in Bavaria, he remarks:

"In addition to the short and frequent botanical and other excursions in the neighborhood, long excursions are made, from time to time, to various parts of the kingdom, the students being accompanied on them by one or more of the professors. Special subjects are assigned to some one or more of the class on which to write out a detailed report. As an example, the last great excursion which took place previous to my visit was made to northern Bavaria, to Nürnberg, and so round to Augsburg, to visit the wool market in that city. In the former city there was, at that time, a great meeting of Bavarian farmers for the discussion of agricultural topics-an agricultural convention, in other words. 'That was taken into ihe trip. That part of the kingdom, as well as Franconia, 
through which the direction lay, is largely devoted to the culture of hops. Now two of the students were appointed to write out an account of the journey in general, three to write on the culture of the hop, two on fruit culture, as seen in the excursion, another on irrigation, another on garlic land, another on the art of manuring, four others on cattle, two others on the visit to Lichtenhof Agricultural School, another on bees, two others on the wool market, \&c. A full report of the excursion is thus made, mostly written by the students themselves, and printed in connexion with the annual report of the school."

In our American industrial colleges these excursions would constitute a most interesting and useful feature. The facility of travel by railroads would enable the students to extend their excursions to cities of great manufacturing celebrity; and the numerous State fairs, with their great collections of so many industrial products, would present the most admirable opportunities for discussions and reports.

3. Character of the soil for the experimental farm.-One of the greatest evils in our present agriculture is the exhaustion of the soil. To stay this by disseminating suclı knowledge of manures and their application, in connexion with deep ploughing and rotation of crops, must constitute a most important part of the practical instruction on the experimental farm. Whenever possible, therefore, a soil of medium fertility, and of such variety of clays and sands as will suffice for the largest class of experiments, should be selected, in preference to a rich soil of a homogeneous character; for this, although more productive in the beginning, would fail in exhibiting the effects of different manures and systems of cultivation and rotation. We agree, therefore, with Mr. Flint in what he says on this point. Speaking of the school at Schleissheim, he remarks :

"The estate consists of about six thousand five hundred acres, and, like many other establishments of this kind, it possesses a fine old royal residence, or chateau, the whole lying in an immense, but not very fertile, valley. I have seen it intimated that the lands were so decidedly inferior and unproductive, that the intention of the government in giving it over to the school to be managed by scientific men was to put the value of scientific principles in agriculture to the severest possible test. I believe, if such was the case, that there has been little reason to exult in the triumph gained over such powerful natural obstacles as a poor soil and an ungenial climate, and I think it may be taken to be as great a mistake to select land for a model farm, or an agricultural farm, that is much below the average of natural fertility, as it would be to select one very much above it. In the first case, even scientific management can hardly be charged with the responsibility of a failure to produce high crops, and in the latter it would not get the credit of what it did produce. Neither would be a fair test of the skill and science applied to it."

- Again, of the lands of the institute at Grignon he says :

"As to the farm, it was not necessary to show the merits of improved culture, and the benefit it can render to the country, to select lands already rich and productive. M. Bella, the first director, refused otlier places which were offered, and chose Grignon, which was noted for its undesirable condition and the poverty of its soil. Many things were in its favor, however. $* * *$ The lands were poor and much worn out, though various in natural quality. Now the lands are worth six times as much as they were when the enterprise began."

4. The number of students. - We have noticed the fact of the small number of students at the European agricultural schools. In this country, where the usefulness and prosperity of collegiate institutions are judged of by the concourse of students, these European schools would not be regarded as either useful or prosperous. Mr. Flint has not discussed the causes of this limited attendance, and we are, therefore, left to conjecture them from incidental observations made by him.

The causes seem to be three in number: 1st. From the fact that there are too many agricultural schools in proportion to that part of the agricultural com. 
munity that desire to receive higher instruction in that pursuit. The nobility who own the land, on the one hand, and the common farm laborers, on the other, do not care for this instruction. It is the renter, or middle man, as he is called in England, who wishes to prepare himself for the proper management of a farm. "The object of the school of practical farming of Jena," says Mr. Flint, "is to give its pupils an education which will fit them for the skilful, practical management of middling-sized and small estates." At Schleissheim, he says, the pupils are the sons of peasants mostly. And, speaking of the price of tuition and boarding of the institute at Cirencester, which was $\$ 150$ per year, as one of the causes of its failure, he says, "Small farmers could not send their sons, and rich ones would not." After creating a debt of $\$ 125,000$, this institute passed under the control of some of the nobility, and the price for tuition and boarding was raised to $\$ 450$ per year, for the obvious purpose of excluding the sons of the middle men. Still it is not prospering.

"The spirit of caste," says Mr. Flint, "so prevalent in England, has probably been the cause of the failure of this college to meet the expectations of the friends of agriculture, or to commend itself to any considerable portion of the people. I could not learn that it was popular with any class." We see here very plainly why these higher agricultural institutes have but a limited number of the farming population in Europe to sustain them.

2d. The second cause is seen in the caste to which Mr. Flint refers.

Neither of these difficulties will exist in this country. Not for farmers alone will our industrial colleges be created, but for all the industrial classes; and as I hope to see them, not for those only, but for all occupations, professional as well as industrial. Caste can only exist in this country by separation, for this begets estrangement; and if we are to have separate institutions for the mental instruction of those following different pursuits, by like reasons we should aim at such separation in moral and religious instruction, and divide into State Catholic and Protestant colleges, and the latter again into Calvinistic and Wesleyan, and Unitarian and Trinitarian.

In Europe the great mass of agricultural laborers do not aspire to ownership of the soil; their condition is one of poverty and servitude, and hence they are not represented in its chief agricultural institutions. But here the industrial classes are owners in fee simple, and their circumstances will enable them to give their children the best instruction. 'The limited number of the agricultural students in European institutions does not, therefore, indicate that a like number only will be the attendance here. The sons of the poorer agricultural classes in Europe are found in schools of an inferior character. "The great majority," says Mr. Flint, "of what are called agricultural schools in Europe are mere manual labor schools, and on a very limited scale at that. In Ireland alone there are one hundred and thirty-four such schools. France has three regional school ons the same footing as that at Grignon, though I believe the two others are not quite so flourishing, one agricultural institute at Versailles, and many inferior schools, carried on in a small way, where, in addition to the elements of education, more or less instruction is given in agriculture, and where the pupils have to work; and this is the case in many other continental countries."

3d. In commenting on the want of success of the institute at Cirencester, Mr. Flint says :

"It only adds another list of instances which might be given to show that success or failure will depend very much upon the man at the head, however great may be the incidental advantages which may occur in favor of such an enterprise." Of the institute at Hohenheim he remarks :

"But as imperfect and defective as were the arrangements at the outset at Hohenheim, there was one thing that neither the director nor the pupils were in want of, and that was an earnest love for their work and an enthusiasm for the high reputation of the new institute. It was not the least of the merits of 
Schwertz (the founder of the school) that he knew how to infuse such an enthusiasm into all his pupils. Where such a spirit reigns, great things are easily developed from small."

An enthusiastic love for the work is, indeed, an essential requisite in those who are to put into successful operation our industrial colleges; and where this is wanting, the power of infusing it into the pupils will also be wanting. To expect suceess where indifference and apathy prevail is folly; zeal and energy, united to enlarged views, must be sought for by those whose duty it will be to give a starting direction to these colleges, in the selection of their presidents and professors.

5. The place of location.-The industrial schools in Europe have not been located in the vicinity of its largest cities. The purpose of this is obvious; for, besides the increased expenses to the pupil, the incentives to waste of time are greater, and the temptations to immorality increased a hundred-fold. The nearness of a city, through its show of great wealth, is calculated to lead the mind of the student to speculative pursuits, and to create a distaste to those industrial occupations whose gains are slow and toilsome.

But in the more retired localities, care should be taken to have in view such market facilities as will insure favorable prices for the products raised or manufactured, and those travelling accommodations which will enable the students to make the excursions referred to.

6. Instruction in the sciences involves a far greater expense in the establishment of an institution than that in languages and mathematics. It requires the museum, by which clear ideas may be communicated through the eye. And this greatly increased expense is one of the prominent causes why the sciences have not been taught in the great majority of American colleges, for on account of their great number the endowment of each has been too limited to have either a museum, or library, or apparatus. Keeping in view this fact, it is obvious that the several States should not only carefully husband the resources derived from the grant of Congress, but should add to it by every proper means. The following suggestions may, therefore, be not inappropriate:

1. Where a State has a well-established university, as that of Harvard or Amherst in Massachusetts, or Yale in Connecticut, or that of the University of Michigan, its industrial college may most advantageously be made such a part of it, as would give the students all advantages of instruction in both, but leave to the Industrial College its own endowment and control. On the question of such connexion, we think the following remarks of Mr. Flint are just. He says :

"I do not know that it would serve any good purpose to enter at length into a development of the controversy now going on in Germany upon this question, owing to the fact, already intimated, that the state of society is so different, the lines of caste there so nicely drawn, and the ohjects proposed in an agricultural education so distinct from our own. But it may be remarked that Liebig has taken the ground very strenuously in favor of a connexion with the universities, and that a majority of the agriculturists adopt that view, or take a middle ground, that the location should be in the immediate vicinity of some established university, partly as a means of bringing the students under university laws, and partly as a means of giving the professors a ligher position in the estimation of their pupils, and of availing themselves of the advantages of the collections, libraries, \&c., which a university can offer, as well as of the talent of university professors."

2. Where a State has no such university, but controls one or more of lesser magnitude, it should so direct its endowment and other means as to make them an integral part of the industrial college. The great expense of properly establishing it has been fully considered in a general way, and referred to more in detail by Professor Owen. It will demand all the educational means of this kind that can be directed to its support to make it what it should be. So far 
from dividing the fund arising from the congressional grant, it should not only be held together, but increased in every possible way. The industrial colleges must, at once, assume the highest rank as educational institutions, or they will. prove most expensive failures.

3. I cannot better conclude this Part than in the closing remarks of Mr. Flint, on the responsibility that now devolves on those whose duty it shall be to establish the industrial colleges:

"The work of deciding this question satisfactorily, and of carrying into operation a scheme of such magnitude as that now proposed in most of the loyal States of the Union, is one of great difficulty and responsibility, and one in which the parties on whom the responsibility rests will need the confidence, the forbearance, and the cordial co-operation of the people. It will require caution, judgment, and practical wisdom on the one hand, and a candid appreciation of the difficulties and the entertainment of reasonable expectations on the other. It will require faith in the application of science to the improvement of practice. We know that it has elevated other arts, improved the appliances of labor, and cheapened the production of the necessaries of life. Why should it not lead, within a reasonable time, to more enlightened processes of farm-work, bring mind and thought to bear upon the labors of the hand, and infuse new spirit into the whole farming community."

\section{PART III.}

[The article which follows, on the museum, the plan and arrangement of the college building, \&c., has been prepared by Professior Richard Owen, of Indiana State University. To no one more competent could it have been committed. It will assist, very much, the several States in determining the details of their industrial colleges, and their necessary endowment. 'This article has in view an industrial college of the first magnitude, but from it can readily be devised one of lesser greatness, or of a less cost, where free tuition is not contemplated. The particular subjects treated of are mentioned in the beginning of his article, and his concluding remarks on the necessity of giving instruction through the eye is, in a most special manner, commended to the reader's attention.]

\section{AN INDUSTRIAL COLLEGE.}

BY PROFESSOR RICHARD OWEN, OF INDIANA STATE UNIVERSITY.

Details of the museum, or school of illustration, and other collateral subjects connected with State agricultural colleges and normal schools.

IN TRODUCTION.

It is proposed, first, to give a few details regarding the model farm; then, concerning the model garden; next, to describe the general plan for the buildings; afterwards, to discuss each department of education somewhat more in detail, including the adjuncts or aids to instruction; then, to offer a scherlule apportioning the duties and salaries among the professors and assistants ; and finally to exhibit an approximate estimate of the entire cost of the buildings, illustrative adjuncis, \&c., showing the amount to be raised by the State, and also the disposition of the annual income, based upon the gift of land, which Indiana would receive from the general goverument, if our legislators agree on fulfilling the conditions. 'The various estimates, \&c., can, from these, if correct, be readily modified for larger or smaller States. A few closing remarks are added on educating the eye, as the best means of obtaining knowledge, also some advice suggested as to the direction which should be given to the student's energies, when he is entering on the duties of life. 


\section{PLAN FOR THE GROUNDS.*}

Let the model farm (including the central garden) comprise, if practicable, exactly one hundred acres, (or, if desired, one hundred and forty, with woodland,) and be of a regular shape. Let a rectangle, fifty rods from east to west, by thirty-two rods north and south, be laid out centrally in that farm. That space, comprising ten acres, is designed for the model garden and the college buildings. The size accustoms the eye to those areas. Let the remainder of the ground, ninety acres, be divided into nine fields, some of symmetrical and geometrical forms, others of irregular shape, but all comprising exactly ten acres. These fields will serve for practice in land surveying, and will facilitate the adoption of a proper rotation of crops, beginning, perhaps, somewhat thus: The garden being No. 1, we may put grass to be cut (say timothy or red-top) in No. 2, on the northwest; blue-grass, north of the garden, for a drill-ground, or for professors' houses, in No. 3; clover, for the first year, in the northeast, making No. 4 ; wheat may be in No. 5 ; barley, rye, or oats in No. 6; corn in No. 7; flax, hemp, cotton, or tobacco in No. 8, a root crop in No. 9. An orchard, No. 10, with osage hedges, in labyrinthian form if preferred, may, by being placed on the west, besides subserving the purposes of instruction in their cultivation, somewhat serve also to shelter the buildings from cold westerly winds.

The corn, another year, might follow the root crop, the wheat the clover, and the meadow be broken up occasionally, and another laid down. Sometimes the rye might be pastured, sometimes cut for grain to mix with breadstuffs, using the straw for thatching hay-stacks; or sometimes, if the field seems to lack organic nourishment, the rye, when of sufficient height, may be ploughed in as a green manure.

\section{THE MODEL GARDEN.}

If this is fifty rods by thirty-two, or eight hundred and twenty-five feet by five hundred and twenty-eight, making exactly ten acres, the fences should be so constructed as to educate the eye; if worm fences, two panels should make exactly one rod; if post and rail, or plank, the posts should be exactly one rod, or eight feet three inches, apart from centre to centre. At forty rods from either end of the long side might be a post higher than the others, to catch the eye and practice it in estimating distances; so of one hundred yards, one hundred feet, fifty feet, \&c. For a similar reason, two pieces of ground may be laid off, so as to show the difference between two acres square and two square acres, or two rods square and two square rods or poles.

The students, aided by the mathematical professors, might lay off the above parallelogram of ground as a geographical garden, on a plan which I first recommended in a communication to the May number of the Tennessee Farmer and Gardener, Nashville, 1856, afterwards reprinted in my appendix to "Key to the Geology of the Globe," published early in 1S5S. By laying the garden off on the plan of Mercator's Projection, and making the prime meridian pass through Behring's straits, the buildings can occupy the central vacancy in the Pacific ocean, while each seed sown, and shrub or bulb plant, may be made to grow on such representative spot in the garden as it occupied in its native soil. It is almost needless to mention that in this garden should be cultivated all the useful and ornamental flowers and fruits.

The prime meridian may be made also to pass exactly through the centre of the observatory on the top; and the long twenty-four-inch wall, to be hereafter

\footnotetext{
* To farilitate the understanding of these and subjoined details, a few ground-plans would have very much aided; but perhaps the verbal description may suffice for comparison with other plans and communications as they come in, until more minute working details are required.
} 
described as running longitudinally from east to west through the building, may have the middle of its foundation exactly on the representative of the equator. Observations may be made from the observatory, and the angles of bearing taken to any given part of the earth, as thus laid down. It may perhaps be permitted to remark, that the line of the prime meridian being arbitrary, some counting from the Greenwich observatory, some from the observatory at Washington, others from Paris, \&c., there would be an advantage in using maps and globes, if all counted the $180^{\circ}$ east and west from the same starting-point or line. A great circle of the earth passing through Behring's straits passes also close to Mont Blanc, the highest portion of Europe, and through or close to the island of St. Thomas, on the coast of Africa, about the spot where the magnetic and terrestrial equators intersect and coincide. This line also nearly represents the greatest north and south elongation of Europe and Africa. Another great circle, exactly 90 degrees from this prime meridian, passes through Asia and America at or near their greatest north and south elongation, as well as near the greatest elevation of land in both continents. 'These straits, therefore, seen to have strong claims upon us for the prime meridiancy. Other and even more important reasons that might be assigned would occupy too much space for this communication.

\section{THE BUILDINGS.}

These might, perhaps, most conveniently consist of one large central building and one smaller, to connect, if desired, by a covered way with the main building on its southeast corner.

Externally the central building might be similar to the Indiana State University, which presents a good architectural effect-a large body, entered by two porticoes and broad stairways, in a contracted appendage to the main body, which again expands into two wings, each stairway leading into the centre as well as into the rooms of one wing. That building cost about $\$ 30,000$. It is of brick, with massive stone foundation, stone comers to all the outside walls, also stone sills and lintels to doors and windows, seventy by fifty-five feet in the main body, and about forty feet high, twelve-feet passages for stairways, wings thirty-six by twenty-five feet, and thirty-four feet high.

For the purposes designed to be attained in the agricultural college and normal school, the main body should be somewhat larger than that of the building just described; say as much as eighty feet long by sixty bruad, exclusive of walls, and about forty-six feet high, exclusive of observatory; while the wings might be the same as in the university, thirty-six by twenty-five in the clear, but thirty-eight feet high.

Not far from the southwest corner might be wood and coal shelters and other out-buildings, some of which might be in pavilion form. Longitudinally from east to west through the main body, but not the wings, should run a two-foot wall, (viz: two bricks and a half thick, which, with mortar, would occupy nearly twenty-four inches; leaving, by the omission of the middle lalf brick, about five inches for the hot-air flues and the cold-air ventilation flues.) 'The former should communicate with a cellar of sufficient size, under the northeast quarter of the centre building, where also means may be devised for keeping the plants, alluded to hereafter, at a sufficient temperature. In this cellar should be large furnaces, heated by coal or wood, to distribute, through this central wall, heat to the fire-rooms in the main body, and perhaps by cross walls, even to the wings; otherwise they may be lleated by stoves in the usual manner. In the large central rooms there should be registers to admit or shut off at option the hot air ; and others, communicating with the cold-air flues, to permit the escape of hot or vitiated air. A similar arrangement should ventilate every room occupied in all the buildings. If steam be deemed a better mode of heat- 
ing, a steam-engine and boilers can be placed on the southwest corner, with the out-buildings, and pipes be laid to convey to each apartment steam to keep up an artificial warmth in winter of about $60^{\circ}$ to $65^{\circ}$ Fahrenheit, on a plan similar to that adopted at the Nashville University, and constructed for the buildings of their literary department by Mr. Miles Greenwood, of Cincinnati.

The plan of a centre wall, dividing the main body into rooms 80 feet long by 30 feet wide, enables us to secure, however, two other advantages, viz: much light from the outside walls, which is greatly wanted for examining, and much room for depositing, specimens of every size and shape. Against this centre wall are to be raised, on heavy trestlework, or on an iron frame, three terraces, making, with the cases on the level of the floor, four ranges in each room of the museum proper; each terrace to have a walk of four feet wide in front of the three upper cases, which occupy two feet in width-consequently, eighteen feet for the three upper terraces, and two feet for the lower cases, thus leaving ten feet for a passage next to the windows, beneath which might be deposited a few large specimens, such as could not enter the cases, yet should occupy a position opposite their appropriate places in the terraces. The ascent from the floor to the terraces may be made by light cast-iron steps and balustrade. The total height of room from the floor, provided we make the cases six feet high, even if we drop the four-foot walks one foot below the back of their anterior cases, would necessarily be four times five, or twenty feet to the ceiling. The glass doors of the cases should slide on iron-rollers. The rooms in the east wing are designed chiefly for lecture-rooms; those in the west are to contain some of the adjuncts, and serve as working rooms for the respective departments.

A. South side of the building.- T'o obtain the necessary height for rooms having four tiers of cases, it is necessary to have only two stories on one side of the building.

a. First story - the geological cabinet.-This is designed to exhibit, in accordance with Professor Dana's text-book-the best yet offered to the public-illustrative specimens of the azoic period in the first row of cases, the paleozoic fossils in the second row of cases, (on the first terrace,) the mesozoic in the third row of cases, the cenozoic in the fourth row.

In the first range of cases, when arranging the most characteristic azoic rocks, we should begin on the lowest shelf of the left case, with the oldest granite or plutonic series, closing that case on the right upper shelf with the plutonic porphyries, which form an easy transition to the second case. Here we arrange the ancient volcanic rocks, in the third case the recent volcanic, and in the fourth case the metamorphic rocks.

In occupying the second tier, or range of cases, with paleozoic fossils, we commence on the left with the lower silurian fossils, and finish on the right with the permian.

In the third range of cases we place the fossils from the triassic to the cretaceous formations, inclusive.

In the fourth range of cases would be found the tertiary and quaternary fossils, from the lowest eocene tertiary on the left, such as we find at Vicksburg, to the remains found in the quaternary deposits of the Ohio, Mississippi, \&c., as the megalonyx, and the shells in the marl, equivalent to the loess of the Rhine, such as those found at Vicksburg, superposed just over the tertiary. The latest quaternary closes the series on the extreme upper shelf of the last right-hand case, as viewed when facing the collection.

If a mineralogical cabinet is to be arranged here, as well as one in the room adjoining the laboratory, there would probably be room for a tolerably full suite of specimens on the right of the azoic rocks, and these mineralogical constituents of rocks should be arranged according to Dana's manual on mineralogy, which is also the best text-book on that subject.

It may not be amiss here to remark, with regard to all collections, that their 
vast extent and variety is not so important, as that they should be characteristic, as, for instance, offering the typical characters of the genera among fossils and animals, and a few well-marked types, in each natural order, among plants.

b. Sccond story - the zoölogical collection.-In this story are arranged all the animals, from the protozoa, the least highly organized, embracing sponges and foraminifers, to the most highly developed mammal, man. The best authors dividing them, according to their nervous system, into four great departments, we would have, in the cases resting on the floor, all the radiated animals; in the second row of cases, the mollusks; in the third, the articulates; in the fourth, the vertebrates.

Not to occupy too much space with details, I will remark that each department would have its lowest class in the left-hand case or cases, and these again the lowest orders on the lowest shelves, beginning with the least highly organized genera on the extreme left of each shelf.

'To aid the eye in learning the subdivisions, different colored cards could be used, placed in little blocks of wood, a few inches long by one and a lialf wide at base, and one high. The gronve for insertion of the card is made by running a sash-saw a few times to and fro, until we have sawed about half way down. To denote subdivision into classes we may use large blue cards with the names in large capitals, (as CLASS I: CEPHALOPODA;) the orders on smaller yellow cards, with names in small capitals, (as ORDER II : TETRABRANCHIATA ;) tribes or families on red cards in italics, (as Family $I$ : Nautilida;) while genera may be marked on white cards, (as Genus: Nautilus,) and the specific name, preceded by the generic, written on strong white paper, (as Nautilus pompilius.) Small specimens should be in small flaring pasteboard boxes. When a shelf, perhaps four feet long and two feet wide, is to hold a number of small specimens, in any department, it is convenient to have two sections made, each half as long as the case, to slide on to the shelf, the section consisting of three or four miniature shelves in terrace-form, each about three inches high and four inches wide.

I have been thus particular in the details of these departments only because I am most familiar with them, believing many of the suggestions are applicable to other branches with which I am less acquainted. In rooms intended for the reception and examination of small objects, the windows should be very high, and as near together as may be permitted without weakening the outer walls; perhaps a cast-iron front would permit the most light to be obtained. 'The windows should be counterpoised, and made to let down from the top, if necessary, with a cord passing under or over a pulley.

B. North side of the building.-'This may be divided into three stories, and have a middle wall rumning north and south from the long longitudinal wall, thus affording at the summit of their junction a firm foundation to receive a granite block for the bed-plate of the telescope appertaining to the observatory on the roof. This cross wall divides each of the eighty feet lung rooms into two, of about forty feet by thirty.

a. Lowest or first story.- The west half is to be filled witl agricultural implements and models, all of the most approved form and useful kind. This room should contain, as already remarked, a sample of all that we would find in a first-class agricultural warehouse. Probably it would be best to have this room terraced also. All the measures of capacity deposited here, such as halfbushels down to pint measures, should have the cubical contents in square inches legibly marked on them, so as, through the eye, to impress those numbers without any great mental effort. The east half of this story is devoted to plants, which, in some instances, might be allowed to grow from the soil and pass through openings in the floor, but would chiefly be arranged in flower-pots on terraces, similar to those recommended for zoölogy. 'Thus the Cryptogamia would be lowest, 'Thallogens on the left, with Protophytes and Fuci on the lowest 
shelves; Acrogens on the right, having the Lycopodiaceæ and Marsileaceæ on the highest shelves. The Monocotyledonous plants would occupy the next elevation, or second range of cases; the Gymnosperm Dicotyledons the third range, and the Anjiosperm Dicotyledons the fourth or last; if too numerous for this range, then the last might encroach on the right of the Gymnosperms or Coniferæ, in range of cases just below, viz., the third.

b. Middle or second story.-The west half is the music-room, with a portion of the wall painted in white staves on a black ground; also with a monochord, for estimating vibrations and explaining the principles of the scale; a metronome, so that time may be definite, not arbitrary ; tuning-forks, pendulums of two different lengths, one to vibrate common time, the other quick time, for drilling young drummers, in connexion with the military organization. Here, too, if an instrumental band could be formed, they would practice and give occasional concerts. In the east half is the drawing-room; it should have numerous plaster figures, besides models of ears, eyes, noses, arms, \&c., also blocks of every size and shape, comprising the geometrical solids. This room should be so arranged as to admit the light from the upper part of the windows; and as perspective should be taught, there ought to be here the usual illustrative apparatus, consisting of threads passing through apertures in a pane of glass, to exhibit the principles upon which the art is based, besides having them theoretically explained in their geometrical studies.

c. Cpper or third story.-In the west half we might have languages, and suspend all around the walls instructive diagrams for general and special history, also outline and ther maps for ancient and modern geography, tabular views, exhibiting analogous parts of language or exceptions, typical form of declensions, conjugations, \&c.; rules for gender, in French and German, \&c., should also be numerously and conspicuously displayed. In the east half we place the department of mathematies, and connect with it all branches of natural philosophy, except such as might more appropriately be taught in the laboratory. The mathematical course should embrace algebra, geometry, plain and spherical trigonometry, mensuration, surveying, and navigation; descriptive geometry, shades and shadows, mechanics, optics, acoustics, and astronomy; also meteorology. By being in the third story the professors and students are nearer to the observatory, and to the meteorological instruments, for daily note and record of changes.

U. A separate building southeast of the main building.-T'his structure might probably be 90 by 65 feet, of two stories.

a. First story - The laboratory for lectures, \&c.-This room should occupy 50 of the 80 feet in length, and be arranged with the necessary furnaces, raised benches for lectures, tables along the sides for students to work at in analyses, \&c. The remaining 30 by 65 feet are to be used for blowpipe analyses of minerals, for experiments in electricity and magnetism, in all their modified forms; consequently there would be cases round the room for a good suite of minerals, (the main mineralogical collection being in the geological room,) both arranged from carbon to gold, according to Professor Dana's text-book; besides a shelf or two to exhibit them, arranged according to their crystals, others to illustrate relative hardness, color, transparency, \&c. One or other of these cabinets should also have models of primary and secondary crystalline forms, a goniometer, and other adjuncts to mineralogy. Other cases could have the apparatus counected with electricity and magnetism in all their modifications. This apparatus could be readily taken into the adjoining lecture-room when wanted. The magic-lantern would probably be more appropriately placed here than elsewhere, so as to use it in connexion with the oxy-hydrogen blowpipe. If the professor of drawing could readily paint slides for it, the magic-lantern could be made an endless source of instruction in all departments.

In one corner should be a balance-room, at least 6 by 10 feet, for all weighing 
connected with analysis, as the delicate balances employed otherwise soon become worthless, from the sharp knife-edge supports rusting, if exposed to acid fumes and corrosive gases.

I may here mention that the microscope would be in no particular department, but in many. The mathematical department should have one to explain its principles and construction; the botanical, to examine plants, sections of wood, and the like; the zoölogical, to investigate bone, muscle, circulation of blood, make embryological researches, \&c.; the chemist, a microscope of the form best adapted to determine some points in qualitative analysis, as distinguishing crystals of potash from those of soda in a minute portion, while solidifying, \&c.

b. Second story.-This, which will be ascended by a broad flight of steps from the outside, is designed as the chapel; also for commencement or similar exercises. It occupies 70 feet of the entire 90 in length, and the full 65 in width, leaving a room 20 by 65 feet for a library, and also for lectures or recitations in religion and moral philosophy. Or, if thought best and means permit, the whole building might be made larger, so as to give more room for the library. The pulpit should be in the middle of one of the longer sides. The heating may be by flues in both walls, and the furnaces be in the cellar, or stoves may be used if preferred. In either case, there should be ventilators, witl movable register plates, similar to those in air-tight stoves.

D. A Normal School building might, if thought advisable, be erected in the orchard, and be constructed of such size and slape as is deemed best; but the expense of buildings might be lightened by having the superintendent of the normal school occupy the lecture-room next to the drawing-room of the main building, and when necessary, also the room adjoining the musical department. In one of these he could lecture and hear lectures from those qualifying themselves as teachers, while they would then be close to all the lecturers, on other branches, whose course the superintendent might designate them to attend. Almost all the instruction would be conveyed by the lectures of these other professors, except the must difficult, and, for them, the most important, the art of communicating knowledge; this it would be the special province of the superintendent to inculcate. This department should be fitted up so as to exhibit the best forms yet contrived for school desks, benches, inkstands, blackboards, arithmometers, and similar articles of school furniture and apparatus.

\section{THE ADJUNCTS.}

Besides the main collections, minor aids, to assist the professors in each department, are very important. Part of these may be, sometimes, most conveniently arranged in lecture and other small rooms, adjoining the main building. A few may be here enumerated:

1. For the Agricultural Department the best implements and machinery, as already mentioned-models of the steam-engine, water-wheels, dams, bridges, barns, sugar-mills, cotton and woollen machinery, \&c. It should liave, besides the models just enumerated, samples of all that would be found in a good agricultural warehouse.

2. The Botanical Department.-Besides the growing plants, there should be many volumes, in elephant folio, of dried plants, systematically arranged; also, tin boxes and screw-presses, $\delta$ c., to enable the students to add to the hortus siccus. There should be charts, exhibiting types of the natural orders, and enumerating some of the most striking characteristics in each. 'To make this complete, we might have on the farm one sample of every important forest tree, either in fence rows or on a spot of ground designed for practical instruction in the nursery culture of fruit-trees, ornamental shrubs, and useful forest trees. In the miseum there should be specimens of every kind of wood, at least all the species useful in the arts. These specimens may be nine inches long, and four 
or five from the centre to the bark circumference, so that by selection of a section from a tree eight or nine inches in diameter, and planing one side, we may exhibit bark, sap-wood, heart-wood, natural grain as split, and grain when smoothed by the plane or polished artificially. All the different kinds of seeds constituting what we usually term grain should be exhibited in clear, widemouthed bottles; samples of all the roots and fruits which will keep, whether used medicinally or for food; a special hortus siccus for the grasses, ${ }^{*}$ tame and wild; the seeds of them separately, in bottles; the gums, balsams, resins, \&c.; different kinds of starch food, as arrowroot, sago, tapioca; coloring matter, as madder, woad, gamboge ; in short, most of the vegetable products found in a city apothecary's and druggist's establishment should all be represented.

3. Zoölogical Department.-In addition to the collection enumerated, part of which should exhibit the osteology of as many vertebrates as practicable, particularly of useful domestic animals, there should be a large aquarium, or several small ones, for studying the habits of mollusks and other animals, jars of alcohol for preserving specimens, a dissecting-table, knives, and other facilities for taxidermy. Diagrams exhibiting the general classification, in one con spectus, of the four departments dependent on the nervous system; also synopsis of each minor subdivision, as the distinctions forming the classes, orders, and genera, based on variations chiefly in the circulatory, respiratory, and digestive organs. The different colored cards, to aid the eye in readily distinguishing the classification, have already been recommended. Diagrams such as those published by Day \& Son, London, giving the whole animal kingdom according to Patterson's classification, and the Extinct Animals, by Waterhouse Hawkins, from the same publishing house, are very valuable. The lecturer on zoölogy might also lecture on anatomy, physiology, and hygiene, as some one must teach that highly important branch, and it connects well with the comparative auatomy and physiology of zoölogy. He should, at all events, have large illustrative plates, such as those of Cutter, or those published by Kelloggs \& Comstock, Hartford, Connecticut. A good solar microscope would also be valuable in exhibiting infusorial and other animalcules to advantage.

4. Geolngical Department.-There should be in one of the smaller rooms adjoining the geological collection a large table especially devoted to the geology of the State in which the college is located. Thus, in Indiana we would have a table, perhaps 16 feet long by 12 wide, on which there might be finely-worked stiff clay or plaster of Paris, laid from two to three inches thick, diminishing to one inch on the lower side of the dip of each formation-consequently in Indiana on the southwest. This material might be painted different colors-say blue for the silurian, (deep for the lower, light for the upper,) red for the devonian, and black for the carboniferous formation, (a lighter shade of black or gray being used for the subcarboniferous.) Upon this clay, or plaster, the specimens would be placed, each in its respective county. The counties could be designated by having their names pasted on, in prominent capital letters. By walking around the table, not only could the geography of the State be impressed, but a correct idea of the geology of the State in which the student then resides could thus be obtained. This department should also have diagrams of the different geological periods, maps on which the coal-fields are, laid down with India ink, models explaining upheaval and the apparent anomaly that the

* By a iypographical error in the former communication, I appeared to recommend the keeping of grapes. It is true I have seen grapes which kept well by being hung in bunches in a cellar, but, for this special purpose, I was recommending a good assortment of all the grasse's to be exhibited to the student for his instruction. At another place, in speaking of healthful diet, it was recommended, by a misprint, to boil meat, whereas I was contending for the wholesomeness of broiled meat, the boiling being lest, not when the meat itself is to be used, but when the nutritious portions are extracted by boiling and found in the water in the form of soup, \&c. 
earliest deposited layers come frequently to form the highest mountain-top ; also Professor Hall's excellent geological chart, an aneroid barometer, Locke's levels, clinometer compasses, geological hammers, small sacks for collecting soils, \&c.

5. Department of Languages.-As so many scientific names are derived from the Greek and Latin, it is very desirable that they should be studied at least long enough to enable us to trace the etymology of terms, even if the student cannot take a full classical course. I will here give a simple illustration: A fossil from the carboniferous formation of St. Louis, described by my brother and Dr. J. G. Norwood, is called macropetalichthys rapheidolepis, which would be hard to remember; but when we know it is from makros, long; petalos, flat; ichthys, a fish ; raphe, a suture; eidos, a form; and lepis, a scale, it is soon as easily remembered as long, flat fish with suture-formed scales.

As regards modern languagès, I am fully convinced, from many years' experience, that for most minds success in their study can be best secured, and progress be most rapid, by adopting some modification of the Manesca, Dufief, or Ollendorf system, originally, indeed, due to Pestalozzi, in which we commence at once to frame short sentences, using a few words on which we ring all the changes, and only bring in portions of grammar by degrees, when both teacher and pupil see the necessity for it, and the latter gratefully receives its aid, instead of being heartily tired out with a long string of rules, usually forgotten before their practical application is called for. Connected with this department should by all means be many charts and other adjuncts, such as Kieport's ancient maps, sold by Westermann, New York; Strass' Stream of Tiine, published by Colton, New York; besides tabular views of typical forms and verbs, nouns, \&c., rules for genders, and the like.

6. Mathematical Department, including natural philosophy, meteorology, and physical geography,-For these the adjuncts would be numerous. Large globes and maps, giving distribution of animals and plants, rain, \&ce., direction of currents, \&c., barometers, thermometers, hygrometers, rain-gauges; diagrams, such as those entered by Isaac Harrington and published by Baker, Orane \& Day, Pearl street, New York; all solids by model, and geometrical figures by paintings on the wall, the arithmometer, the camera obscura, abundant mathematical instruments for architectural drawing, the protractor, a quadrant, sextant with horizon, sirene, optical instruments, a room that can be darkened for optical experiments, and a model such as could easily be contrived for making the principles of descriptive geometry intelligible to those who have not much imagination. On the top of the building, as already stated, an observatory is to be constructed. The means could be readily devised for suspending, from a cranelike rod of iron on the roof, a pendulum, far enough off to make correct observations for the variation of the compass. An awning might be stretched over part of the flat roof, at a height permitting many observations to be made, without the dew falling, either on the observer when using the theodolite, or on the artificial horizon when he is using it with the sextant. I will here further suggest, that there might be a stout frame of wood, or iron, covered somewhat like a balloon, but with stout material; which frame, in its total, should represent somewhat more than the northern hemisphere. It might show to those standing inside the apparent position of the prime meridian, the ecliptic, the equator, (coinciding with the height of the eye,) and all the most important constellations or assemblages of stars. These could be represented on the inside of the oiled-silk or canvas cover, which would have either to be susceptible of removal, in case of a threatening storm, or be protected by some movable shelter over it. The constellations, either painted, or the stars composing them indicated by gold or silver paper glued on, might be made to represent the position of the heavens at the time the observation is made, by having this hollow celestial globe to pivot, at zenith and nadir, on a strong central axis. After examining inside, the student would step out and observe the extension of lines continued 
in the same direction, and thus, it is believed, a knowledge of the constellations could be readily obtained, a correct conception of the zodiac be formed, and a familiarity with many celestial phenomena be acquired. With the aid of good chronometers, sextants, theodolites, \&c., students could be made acquainted with the principles and practice of observing for latitude, longitude, variation, dip, intensity, and other phenomena.

In the normal school, in order to give a correct idea how to teach geography, it is recommended that the students, who are to be future teachers, should measure the garden, and lay down on paper a ground-plan of the same; then measure and plot the farm; next, the township. 'Then, even without measuring, they may, from the county surveyor's field-notes, make a map of the county, marking its townships and its county seat; then one of the State, giving the range lines east and west of their principal meridians, the township lines north and south of their base, also all the county seats and principal rivers; next, an outline map of the United States, giving principal rivers and mountains, also all the State capitals ; finally, a map of the world, with the lines of latitude, longitude, the equator, tropical, arctic, and antarctic circles, preceding the whole by a full explanation to the professor how a hemisphere can be represented on a plane surface, so that he may judge of the correctness of their ideas, and their consequent ability to make the subject clear to others.

7. Department of Chemistry.-Besides having all the purest reagents and best modern facilities for teaching the student accurate qualitative and quantitative analyses, assaying, \&c., this department should give some knowledge of practical arts, such as soldering, silvering, gilding, ink and soap making, dyeing, and the like, at least so far as to make the student understand the principles thoroughly; and it should also render familiar the taking of specific gravities, applied to solids. liquids, and gases, also the gauging of contents, in vessels of different shapes, \&c, All the substances should be labelled with the full name, and give the composition in chemical symbols. Youman's and Foster's charts should hang constantly in view. Although the remark does not apply especially to the laboratory, I may here observe that everytling used should, as far as practicable, be definite, determinate in size and shape, to convey information, chiefly by appealing to the eye. For instance, on the upper part of the wall, not used for blackboard purposes, might be diagrams, suspended or painted on the plastering, to represent one hundred square inclies, ten square inches, an English foot, a French foot, a French metre (39 $\frac{37}{100}$ English inches,) a tabular comparison of French and English measures and weights; also of Fahrenheit's, Reaumur's, and the Centigrade thermometers; synopses of some important chemical bodies, giving in different columns, 1 st, the name; $2 \mathrm{dly}$, the symbol; $3 \mathrm{dly}$, the atomic weight; 4 thly, the specific gravity; 5thly, how obtained; 6thly, how distinguished; 7 thly, for what used; also tables, giving the apothecary's hieroglyphics, comparison of troy and avoirdupois weights, \&c. In the same manner, on the upper part of the walls in the mathematical room, might be painted triangles, parallelograms, \&c., giving briefly, in the interior space of the figure, the rule for calculating its area.

\section{FSTIMATE OF EXPENSES.}

Many merchants spend $\$ 50,000$ in building and furnishing private dwellings for themselves and families. Not a few expend $\$ 50,000$ on the house, and $\$ 50,000$ on the furniture and the appurtenances, for interior and exterior ornament. It would appear, then, not to be demanding an unreasonable appropriation if we ask double that sum from a great and flourishing State for the facilities necessary to diffuse knowledge, spread morality and true religion, educate the soldiers' orphans, and prevent crime, when a State unlesitatingly appropriates those or larger sums for the erection of penitentiaries to punish the 
crimes which might, by a rational and generally diffused system of thoroughly training the body, mind, and morals of every child in the State, be almost altogether prevented.

On the plan of buildings proposed, I sincerely believe, knowing that the Indiana Univergity was built substantially, and after the rules of good architectural design, for $\$ 30,000$, that $\$ 50,000$ would be ample to erect the main building, as described abore, and $\$ 50,000$ more, well expended, would supply it with most of the contents enumerated. The chapel and laboratory could be built for $\$ 15,000$; and $\$ 10,000$ might be set aside for out-houses, dwellings for head gardener and head farmer, also for a barn and stable, viz: \$2,000 for the two dwelling-houses, $\$ 1,000$ for the out-buildings, $\$ 4,000$ for a barn, and $\$ 3,000$ for stable and cow-louse, including sheds and shelters for sheep, hog-pens, \&c. 'Thus $\$ 125,000$ might be made to suffice; but it would be much better if the State could appropriate $\$ 200,000$ to secure the following advantages: It would be very desirable to have the farm well stocked, and to have the means of making all the farm repairs on the premises, without encroaching on the principal given by the general goverument. As every citizen in the State is to be benefited, he can well afford to tax himself once pretty lieavily for this purpose, while even then it is less than 20 cents apiece for every man, woman, and child in the State of Indiana, according to the census of 1860 . If then we add $\$ 25,000$ more to the above $\$ 125,000$, we could erect wagon and blacksmith shops, and secure all necessary adjuncts; also procure the best stock to the extent necessary for a farm of the size designated.

By taking $\$ 25,000$ more, we could erect on a ten-acre lot ten moderate-sized dwelling-houses, not very distant from the centre building. These might cost, each $\$ 2,500$, fence and out-buildings inclusive, and could be rented to such professors as lad families for 6 per cent. on the cost-consequently, $\$ 150$ per annum-and thus bring in annually $\$ 1,500$, which might form an addition to the fund hereafter mentioned for the gratuitous board and tuition of soldiers' and sailors' orphans. 'These amounts and expenditures would, in case of a $\$ 200,000$ appropriation, still leave $\$ 25,000$ for a contingent fund to be used, provided some of the above estimates are too low ; but they are believed ample, with the surplus of $\$ 25,000$; therefore, I would suggest that a farm of 100 acres be purchased near the college, at a cost of, perhaps, $\$ 25$ per acre, making an expenditure not to exceed $\$ 3,000$; further, that a large, plain, frame schoolhouse be erected, with dormitories, a few class-ronms, a mess-hall, and a kitchen, to cost $\$ 4,000$. One thonsand should furnish it with school apparatus, beds and bedding, chairs, tables, and cnoking utensils, leaving $\$ 17,000$ to be invested at 6 per cent., thus to bring in annuslly about $\$ 1,000$. This farm and school to be for children of the State rendered orphans by the war; to support them chiefly by their own labor; give them industrious habits, and prepare them for the more extended education in college. Their daily duties might be, 8 hours labor, 4 study, 3 recreation, 1 for meals, leaving $S$ for sleep; and it is known, from practical experiments made by Mr. Fellenberg in Switzerland, that, after ten years of age, they could support themselves. 'The county coinmissioners could defray their travelling expenses to the central school out of the county funds. 'The chicf requisite to success would be to find two men who should direct the stndies and labors of the youths, say 100 or thereabout, partly in consideration of the $\$ 1,000$, but more from the natural benevolence of disposition, which would make it a pleasure to be the companions of orphan children. 'The countics sending might make up deficiencies pro rata.

Having thus spoken of the disposal of the State appropriation, be it $\$ 100,000$ or $\$ 200,000$, we proceed to show how far the grant of Congress, which, by the provisions of the act, cannot be expended in buildings, would be best disposed of to meet other requirements. The amount for Indiana is 390,000 acres of land, which, at a low estimate, would realize $\$ 300,000$, and might readily net 
over $\$ 400,000$; consequently, even after expending from $\$ \$, 000$ (160 acres of land at $\$ 50$ per acre) to $\$ 16,000$ (160 acres at $\$ 100$ per acre) for land, we might still safely count upon an annual income from the investment, funded at 6 per cent., of from $\$ 18,000$ to $\$ 24,000$. Let us, however, base our calculations on the average, $\$ 21,000$, and expend it as follows:

For fuel, light, repairs, and incidental expenses............. \$2,000

For salaries of professors, assistants, and employés .......... 19,000

'Total

The salaries, which should be high enough to secure good talents, but not to encourage excessive disparity in remuneration, might be thus apportioned:

Superintendent or president of agricultural college........... \$2,n00

Superintendent or president of normal school.............. 1,500

Professor of mathematics........................ 1,500

Professor of chemistry ........................ 1,500

Professor of ancient languagew...................... 1,500

Professor of natural history . ..................... 1,500

Adjunct professor of mathematics.................... 1,000

Adjunct professor of chemistry .................... 1,000

Adjunct professor of natural history .................. 1,000

Professor of modern languages...................... 1,000

Instructor in music ................................. 1,000

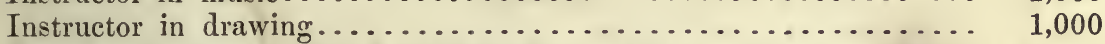

Instructor in tactics and sword exercise................. 900

Head farmer, a house and......................... 700

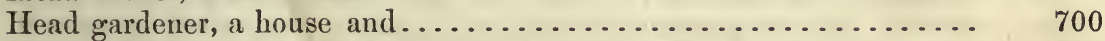

Expert farmer, who must be a good sheep-shearer............ 450

Expert farmer, who must be a good mower................ 450

Porteress, who may be the wife of any one of the last four enumerated.. $\quad 300$

Total............................ 19,000

If the funds permitted, it would be very desirable to have a taxidermist, who could keep up the collection, and instruct the students in stuffing and setting up animals.

'Ihe duties of the above corps would be about thus divided :

\section{Professors and assistants.}

1. The president would lecture on Sunday, and impart religious instruction, devoid of sectarian bias; lecture on sacred history and moral philosophy ; preside at faculty meetings, and have a general care of the welfare of the agricultural college.

2. 'The superintendent of normal school would, as remarked, give his chief attention to have the normal school students master the art of conveying the most useful instruction in the manner best calculated to make it impressive and attractive, and to facilitate its most ready acquisition.

3. The professor of mathematics would lecture on or teach plain and spherical trigonometry, descriptive geometry, optics, acoustics, mechanics, navigation, and astronomy.

The adjunct in this department would teach algebra, geometry, bookkeeping, physical geography, and use of globes, surveying and moteorology.

4. The professor of chemistry would lecture on heat, light, electricity, and magnetism, organic and agricultural chemistry, and superintend the operations of the most advanced analytical students. 
The adjunct should teach inorganic chemistry and the use of the blowpipe; also superintend the analytical labors of less advanced students.

5. The professor of natural history would be expected to teach human anatomy and physiology, comparative anatomy and vegetable pliysiology ; also geology and palæontology, and perhaps veterinary surgery, unless the funds permitted the employment of a surgeon to superintend the health of the estab. lishment, who could then take this as a specialty.

The adjunct professor would instruct in practical botany, zoölogy, mineralogy, and taxidermy.

6. The professor of ancient languages would teach Greek and Latin, in connexion with ancient geography and mythology.

The assistant, or professor of modern languages, would instruct, such as desired, in German, French, or Spanish.

7. The duties of the instructors in music and drawing have been already pretty fully discussed. Were not economy an object, one artist could be kept fully occupied making large paintings in the style used for stage scenery, and in lettering large diagrams for each department.

8. The instructor of tactics should form a class of the most capable, and drill them thoroughly, so that they could afterwards, as officers and non-commissioned officers in the corps of students, aid lim in drilling every student one hour daily.

\section{Employés.}

9. 'The head farmer should be thoroughly conversant with the principles and practice of ploughing and sowing by hand; should understand keeping farm accounts, the management of reapers, mowers, and other labor-saving machinery, and the rotation of crops.

10. The head gardener must understand the cultivation of plants in a hothouse and green-house, budding, grafting, and pruning, and be thoroughly conversant with the cultivation of the ordinary vegetables, flowers, and fruits.

11. One farm hand should be able to manage stock generally, and lie capable of showing the students the principles and practice of sheep-shearing. 'The other should be a good reaper, mower, and cradler, and be able to show students how to grind and hang a scythe, adjust the implement to his height, and take a clean swath. These two hands labor on the farm in summer; in winter they attend to the stock, make fires, and act as janitors for the recitation-rooms.

12. The porteress busies herself chiefly about dusting and keeping everything in gond order in the museum. She ought also to attend strangers visiting the college who desire to examine the museum out of curiosity, not rendering it necessary to disturb a professor or assistant, unless they request special information. The room next the agricultural collection might be assigned to the porteress, with a fire to make visitors comfortable in winter.

\section{VI.-CONCI.UDING REMARKS.}

Being fully sensible that this communication has extended much beyond the simple details asked for regarding a museum, I feel yet so fully impressed with the vital importance of the subject of education, and with the feeling that not one half has yet been said which rises before me demanding a hearing, that I crave indulgence while I make a few closing observations :

If the students are all received without charge, as contemplated on this plan, there should be some ratio per county or district guiding their reception. Suppose, then, that besides the soldiers' orphans, as mentioned below, there should 
be from every county, four students selected every two years by the county commissioners from among those who had the strongest recommendations in the graded or other public schools for diligence, progress, and morality. 'Thus, if the course lasted two years, there would be in Indiana, which has 92 countics $4 \times 92=36 \mathrm{~s}$ students, besides the orphans, making a total attendance probably of between four and five hundred at the two institutions.

There is a plan by which the expense may be diminished, or rather the means increased. The farm is to be worked by the students, under the direction of the head farmer and his two farm hands; the garden and orchard are also to be cultivated by the students, under direction of the head gardener, and assisted by such professors as desire to improve their physical health and energies. The proceeds of this labor, if everything is well managed, ought to be, at least, from one to two thousand dollars per annum. This sum may go to swell the column for annual expenditure; but it is suggested, as better, that it should be used to keep up a boarding-house, at which unmarried professors and students could board at a fair price, thus creating at once a market for their own produce. But the chief advantage of this plan yet remains to be explained: That the children rendered orphans by the war (whether the lower graded school for orphans be adopted or not) should, besides here receiving gratuitous instruction to fit them for occupying highly respectable positions, be also gratuitously boarded out of the profis of the farm, garden, and boarding-house. A thorough education would benefit them and the community much more effectually than a donation of land or money.

I ouglit not to omit mentioning that every opportunity should be embraced (professors sharing the labor equally and making themselves the attached companions of their pupils) to take a class or two at a time, say Saturdays, to see the useful arts and manufactures carried on, by visiting the neighboring printing and bookbinding establishments, foundries, dye-houses, cotton and woolen mills, grist mills, tanyards, breweries, \&c.; and if it is a walk of five or six miles to these, so much the better.

The students should also be encouraged to imitate what they see by making models in wood, sometimes modelling in clay or wax designs they may have sesn ; also in painting, in the cheap and rapid distemper style, above alluded to, typical forms, tabúlar views, \&c.

If any one objects to the main feature of the above plan, the education of the eye, as claiming undue pre-eminence, I have one argument, which, to my mind, is very powerful, and may be so to that of others. I hope, therefore, I shall be pardoned for introducing it here, even by what may appear a digression.

The nerves give energy and direction to all organic and animal life in manThe nerves of the special senses, emanating from the brain, are the chief sources, or means, of knowledge and enjoyment. Of the 12 pairs of cranial nerves, the second pair, (optic nerve,) the third pair, (motores oceulorum,) the fourth pair, (patheticus,) the oplithalmic branch of the fifth pair, (tri-facial,) and the whole of the sixth pairs, (abducentes,) are devoted to the various func. tions and motions connected with the "windows of the soul," the eyes. The ear is supplied by the auditory nerve, a few filaments from the facial, with a minute ramification from the pterigoid branch of the trigeminus. The nose receives a single pair, the olfactory, and a minute branch of the ophthalmic, while our whole taste is dependent upon the gustatory nerve, a small ramification from the third branch of the fiftl pair, aided slightly by a portion of the glosso- 
pharyngeal.* Others are involuntary, and regulate our breathing, digestion, \&c. 'The sense of touch has 31 pairs of nerves, besides a few branches from the brain. These 31 emanate from the spinal cord, one in each pair serving to give motion to our muscular system, the other to convey information back to the brain, chiefly regarding lieat, cold, size, shape, and resistance of bodies, thus correcting sometimes impressions made through the eye, but chiefly ministering to our necessities and to the preservation of life. 'The Supreme Architect seems, therefore, in His omniscience to have designed that we should use the eye and the touch as the most important means of obtaining knowledge; and next to those the ear. My own experience, after a daily practice of about twelve years, or indeed (including four years' military instruction given in the manual of arms and drill) of sixteen years, devoted to the best means of imparting instruction, fully justifies me, I think, in stating that I would sooner undertake to impart, thoroughly, certain kinds of knowledge through the medium of the eye, aided by short explanations, extending through one hour each day, for six months, than by mere oral descriptions, given daily one hour for twelve months, thus saving half the time.

The following definition of a prism is very excellent, and very useful after a child has seen one: "A prism is a solid, the ends of which are polygons, and the side faces of which are parallelograms." But what idea would most clildren have of a prism by simply liaving this repeated daily tèn times, for ten succes. sive days? Not as clear a conception as from seeing it only once. And if the definition, given for the first time, were a bad one, or defective, the idea would, perhaps, be so confused that no subsequent good descriptions would serve to clear the difficulty.

What I earnestly contend for is, not the exclusion of any of the ordinary modes of conveying information, but the preceding of them by ocular instruction. When the child requires exercise it should be taken out, and the eye be educated by familiarizing the young mind with the names and properties of the thousand interesting objects around us. This task would require too much time for each parent to fulfil it, but the knowledge could be acquired by a whole large class at a time, from nature, aided by the remarks of a thoroughly qualified companion teacher; and that, too, in the early years of our lives, without mental effort, but requiring at a later period hard intellectual labor. It is thus the backwoodsman learns in early youth to know every tree of the forest. It is thus the children of the Russian nobility learn three languages from three nurses as easily as ours acquire one. It is thus that all of us become, without any effort, familiar with certain objects that constantly surround us, and might as readily know the names and properties of five or even ten times as many things around us, without labor, had we always had in youth some intelligent companion or teacher to give us the information, in connexion with the objects, just when we wanted it.

If the above statements are facts, then it behooves us to educate the eyc, to familiarize the cliild, at an early age, with all the objects of interest that surround us, until, as the mind expands, it gradually acquires an extended knowlledge of the wounderful works of creation, and is thereby led to recngnize and adore the immutability and perfection of the laws by which the Deity governs the universe, obedience to which will insure virtue and happiness.

If we could, as a preliminary to this training in the agricultural college, liave pupils well grounded by State normal teachers, county, township, and district schools, all taught on the same system, in useful facts, and giving attention to the various keys to knowledge as means, not ends, husbanding all our educa-

* The last enables us to taste with the back part of the tongue and palate. A few filaments from the 12th pair of nerves (the hypoglossal) give motion to the tongue, serving, however to modify speech, not contributing, apparently, to the discernment of quality in food. 
tional resourees, and putting them under State management, somewhat on the plan I recommended in a series of articles on education twenty-four years since, then our'labor would be much lightened, and progress be much greater. We ought still, however, to precede the studies at these schools by insiruction to the infant mind, as introduced by my father forty years since, and as now practiced in parts of Germany, where mothers are relieved of the care of their children during the day, and the infants play in well-arranged grounds and gardens, where their attention is directed to the acquisition of many facts, without any strain on the young brain.

As our young men progress in the agricultural college they should be advised to select the occupation they design to pursue, and make their chief studies bear on that main object, the others being collateral. 'To those who select law, and design by close study and forensic eloquence to take a prominent position, we miglit impress many useful facts regarding the prevention of crime, showing also that the chief object should be to correct vice, and prevent its evil effects on society, rather than solely to punish the criminal, and that his duty should be to allay, rather than augment any breach between neighbors.

The youth who designs becoming a plyysician might be cautioned to study nature, and aid his patients to recover health rather by the inculcation of correct hygienic rules, than by a resort to powerful therapeutic agents. He should also be led to see the vital importance of bringing his influence to bear against the intermarriage of near blood relatives.

On the future merchant or citizen selecting manufactures and the like, as a source of wealth, let the lesson be impressed that wealth is a means, not an end in life, and that happiness is never secured by selfishness.

The politician should be cautioned against inordinate desire for distinction; be taught that zeal should discuss principles, not lead to personal abuse; that patriotism goes transcendently before partyism; that office should seek us, not we grasp at office; and that true liberty consists in having every man, after he has heard the arguments, exercise the elective franchise without fear or favor.

On the future expounder of the beautiful teachings of Christianity we cannot too forcibly impress the necessity of conforming his own practice to the doctrines inculcated; of preaching and living "peace on earth and good will toward all men." He may impress, with all the enthusiasm his nature dictates, his own doctrines and views on the mind of his reighbor; but let him beware of condemning the equally sincere convictions of that neighbor, leaving judgment to the Omniscient Maker and Interpreter of divine laws, who alone knows the most secret workings of the human heart. Let those whose praiseworthy aim it is to become spiritual advisers, learn while young to practice that forbearance which they claim for themselves, to extend forgiveness of enemies with the fullest force of its scriptural inculcation, and daily to exercise that divine charity, that celestial love, which is the connecting link between mortality and immortality, the bond of union between finite man and his Eternal Maker.

It may here be asked, after reviewing the subject, why, as one great object in education is to develop a sound mind in a sound body, more has not lieen said about physical training. The reply is: Solely because it was believed this system would naturally furnish so much active out.door exercise, that it was unnecessary to make a special business of taking exercise. The industrial system and military drill, if properly carried out, would insure that good health, witlout which all the rest is of no avail.

Neither has much been said about the most important of all, the moral culture, because it was thought that a system which would make teachers and taught trusting companions, which would induce each and all to investigate the works of nature, to discover truth and riject error, to admire the design and perfection exhibited in all the works of the adorable Creator, would be a solid 
foundation for morality, and would, in conjunction with the unbiased religious and moral instruction designated in the curriculum, leave the student's mind in the best condition to approacin the consideration and investigation of different tenets. Thus prepared he could examine them with zeal, yet with moderation; with judgment, yet without dogmatism; with an inquiring mind, desirous to trace final causes, as far as human intellect may venture, yet with the deepest awe of the majesty, the highest appreciation of the perfection, and the most unbounded confidence in the works, laws, and infinite goodness of the Supreme Ruler, to whom frail mortality, after prayerfully striving to find truth, fulfil his duties and understand the fundamental doctrines of religion, may, without a shadow of hesitation, trustingly consign his temporal and eternal welfare. 


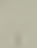

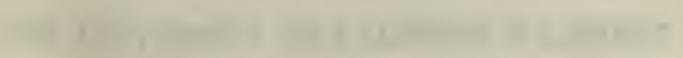
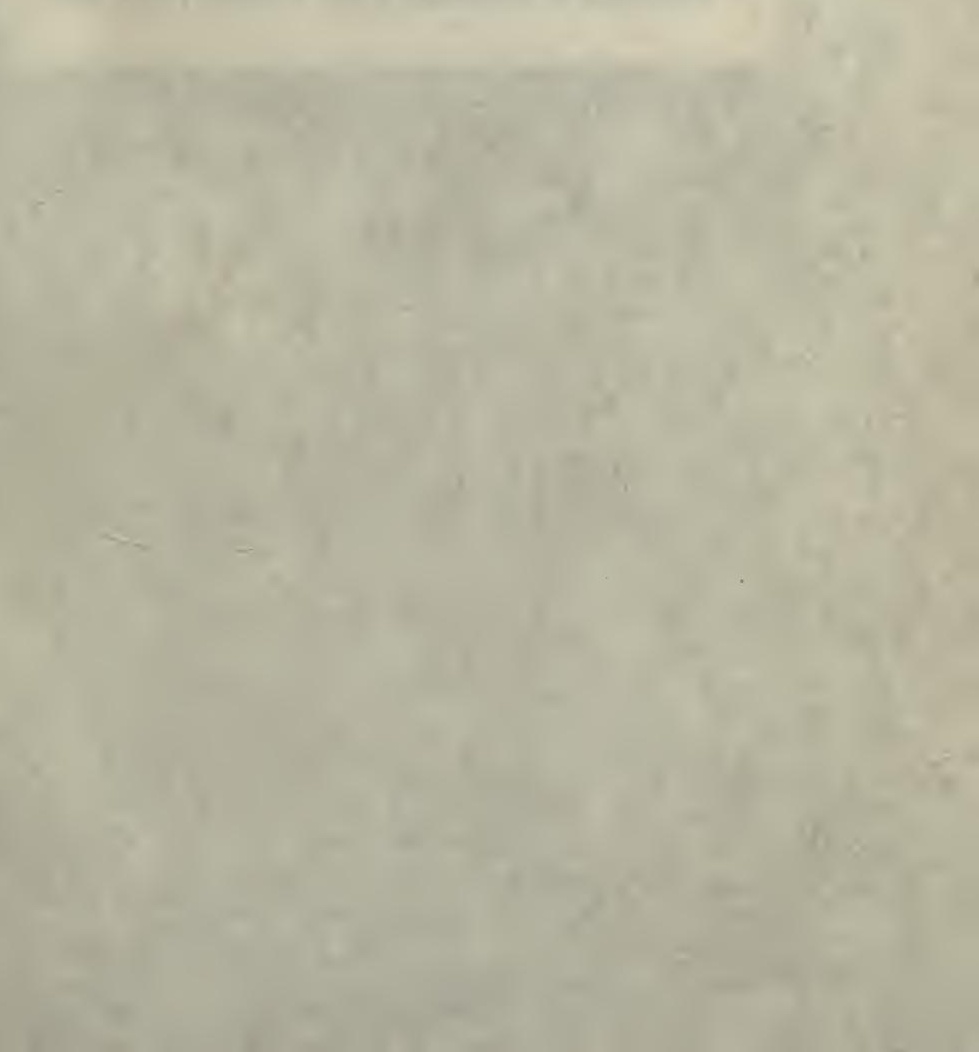

Gaylamount

Pamphlet

Binder

Gaylord Bros., Inc.

Stackton, Calif.

T. M. Reg. U.S. Pat. Off.

\section{$\bar{M} 105118$}

5533

$B 6$

THE UNIVERSITY OF CALIFORNIA LIBRARY 


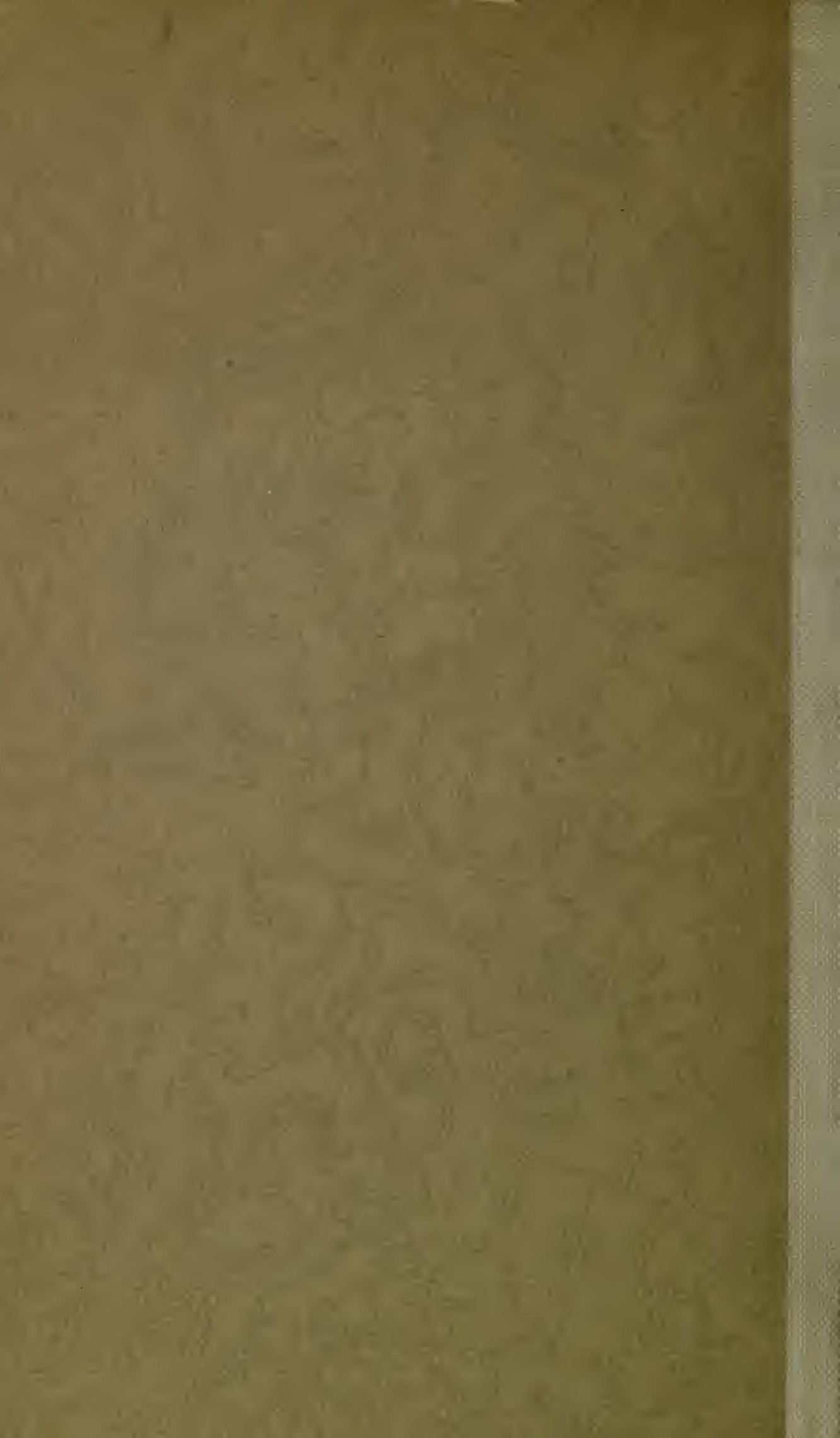

